\title{
Discharge Chamber Plasma Potential Mapping of a 40-cm NEXT-type Ion Engine*
}

\author{
Daniel A. Herman ${ }^{\dagger}$ and Alec D. Gallimore." \\ Plasmadynamics and Electric Propulsion Laboratory \\ University of Michigan, Ann Arbor, MI 48109 USA
}

\begin{abstract}
Floating emissive probe plasma potential data are presented over a two-dimensional array of locations in the discharge chamber of a $40-\mathrm{cm}$ diameter ring-cusp ion thruster. The data rule out the presence of a potential-hill plasma structure downstream of the discharge cathode assembly (DCA), which has been proposed as a mechanism of high-energy ion formation leading to DCA erosion. The discharge potential structure is dominated by the magnetic circuit, which reduces the diffusion of electrons across magnetic field lines. Shorting of the discharge keeper to discharge cathode common does not have a detectable effect on the near-DCA plasma structure outside of the keeper sheath. The plasma potential structures are insensitive to thruster throttling level with a minimum as low as $14 \mathrm{~V}$ at the DCA exit plane increasing gradually in the axial direction, but rising abruptly in the radial direction. A sharp increase in plasma potential to the bulk discharge value (a few volts above the discharge voltage), is observed in the radial direction past the discharge keeper edge. The existence of a free-standing plasma potential structure, termed a double layer, is found to form the transition between the low-potential plume emanating from the discharge cathode and the high-potential bulk discharge plasma. Angular-dependent sputtering yield calculations are used to estimate the NEXT DCA wear rate for the operating condition of the 2000-hr wear test. The calculated erosion rate $(49 \mu \mathrm{m} / \mathrm{khr})$ is slightly lower than the observed keeper erosion rate in the NSTAR 2000-hr and 8200-hr wear tests. This is due to a decreased double-to-single current ratio measured in the beam of the NEXT thruster at the wear test operating condition compared to the measured ratio in the beam of the NSTAR thruster at the full-power throttle point.
\end{abstract}

\section{Nomenclature}

$=$ magnetic field magnitude, Gauss

$=$ effective exhaust velocity, $\mathrm{km} / \mathrm{s}$

$=$ emitting filament wire diameter, $\mathrm{mm}$

$=$ incident ion energy (normal), $\mathrm{eV}$

$=$ threshold energy for sputtering, $\mathrm{eV}$

$=$ gravity constant at sea level on earth, $\mathrm{m} / \mathrm{s}^{2}$

$=$ specific impulse, $\mathrm{s}$

$=$ acceleration grid current, $\mathrm{mA}$

$=$ beam current, $\mathrm{A}$

$=$ discharge current, $\mathrm{A}$

$=$ neutralizer keeper current, $\mathrm{A}$

$=$ initial mass of spacecraft (including propellant), $\mathrm{kg}$

$=$ final mass of spacecraft (dry mass), $\mathrm{kg}$

$=$ propellant mass flow rate, $\mathrm{kg} / \mathrm{s}$

$=$ base pressure (air), Torr

$=$ corrected pressure (xenon), Torr

$=$ indicated pressure (xenon), Torr

${ }^{*}$ Color copies available at http://www.engin.umich.edu/dept/aero/spacelab/publications/conf_pub.html.

${ }^{\dagger}$ Graduate Student, Aerospace Engineering, hermo@engin.umich.edu, 1919 Green Rd Room B107, Member AIAA.

* Professor and Laboratory Director, Aerospace Engineering, Alec.gallimore@umich.edu, Associate Fellow AIAA. 


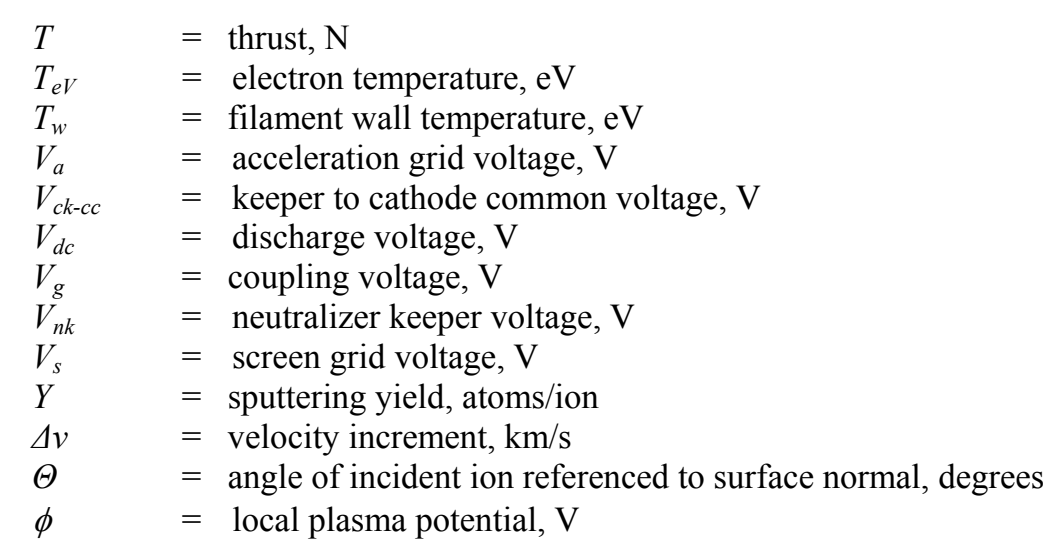

\section{Introduction}

T

HE motivation for high exhaust velocity propulsion technology investment is illustrated by the Rocket Equation or Tsiolkovsky's Equation. Named after famous mathematics teacher Konstantin Tsiolkovsky, who in 1903 first published its derivation, the Rocket Equation identifies exhaust velocity as the important performance parameter in rocket propulsion. ${ }^{1}$ The Rocket Equation illustrates that the fraction of the original vehicle mass that can be accelerated through a given velocity increment, $\Delta \mathrm{v}$, is a negative exponential in the ratio of that velocity increment to the effective exhaust velocity, c.

$$
\frac{M_{f}}{M_{i}}=e^{-\frac{\Delta v}{c}}=e^{-\frac{\Delta v}{I_{s p} g_{0}}}
$$

As illustrated in Eq. 1, the effective exhaust velocity is related to the performance parameter specific impulse, Isp, which is defined as the total impulse per unit weight of propellant, given by Eq. 2 .

$$
I_{s p} \equiv \frac{T}{\dot{m} g_{0}}=\frac{c}{g_{0}}
$$

Tsiolkovsky's Equation, Eq. 1, establishes the need for an effective exhaust velocity that is comparable with the mission $\Delta \mathrm{v}$ if a significant fraction of the original mass is to be brought to the final velocity. Deep space missions are prime examples of high- $\Delta \mathrm{v}$ missions that benefit from high exhaust velocity, but this can also be true for northsouth station-keeping (NSSK) requirements in which long satellite lifetimes may require substantial $\Delta \mathrm{v}$ 's to overcome the solar radiation pressure drag and gravity gradients to maintain their orbit. It is clear that there are many missions that can benefit from high exhaust velocity, or equivalently high specific impulse, technologies.

Ion thrusters are high-efficiency, high specific impulse $\left(\mathrm{I}_{\mathrm{sp}}\right)$ propulsion systems that are being proposed as the primary propulsion source for a variety of missions. Ion thruster technology has enabled new missions that had not been feasible using liquid propellant rocket technology. The NASA Solar Electric Propulsion Technology Applications Readiness (NSTAR) 30-cm ion thruster was the first ion engine to be used for primary spacecraft propulsion in the Deep Space One (DS1) mission, validating ion thruster technology maturity for space flight. With a design lifetime of 8,000 hours, the NSTAR ion thruster accumulated 16,265 hours of operation in space and the flight spare accumulated 30,352 hours of continuous operation in ground-based testing., ${ }^{2,3}$

A key component of the NSTAR program is ground-based testing of engineering model thrusters (EM's or EMT's) for extended periods of time. The first wear test of an engineering model $30-\mathrm{cm}$ NSTAR thruster was the full-power $(2.3-\mathrm{kW})$ 2000-hour wear test conducted at the NASA Glenn Research Center (GRC). The 2000-hour test, which did not employ a discharge cathode keeper, revealed extensive erosion of the two discharge cathodes used during the test. ${ }^{4}$ Subsequent 1000 -hour wear test and 8200-long duration test (LDT) employed a sacrificial keeper electrode demonstrating reduced discharge cathode erosion at an acceptable level $(\sim 60 \mu \mathrm{m} / \mathrm{khr}){ }^{5-7}$ An Extended Life Test (ELT) of the NSTAR DS1 flight spare thruster, conducted at the Jet Propulsion Laboratory (JPL), revealed extensive keeper erosion that has yet to be fully explained. There is a lack of understanding of the 
discharge cathode assembly (DCA) erosion phenomena in ring-cusp ion thrusters. Engineering solutions, such as thicker keeper electrodes and more exotic keeper materials, may not be sufficient to achieve desired ion thruster lifetimes for future missions requiring several tens of thousands of hours. ${ }^{8} 9$ A detailed understanding of the discharge plasma environment in ion thrusters will lead to better discharge designs and DCA erosion mitigation methods.

The successful demonstration of the NSTAR ion engine provides an off-the-shelf 2.3-kW ion engine suitable for discover class NASA missions. Several missions under consideration for the exploration of the Solar System have identified higher-power, higher-throughput $5 / 10-\mathrm{kW}$ ion propulsion systems as a requirement for feasible missions. ${ }^{10}$ For larger flagship-type missions, specifically robotic exploration of the outer planets using 25 -kW-class solar-powered electric propulsion, NASA GRC has led a team to develop the next generation ion thruster. The 40$\mathrm{cm}$ xenon ion engine, termed NASA's Evolutionary Xenon Ion Thruster (NEXT) was selected in 2002 for technology development as part of the Next Generation Electric Propulsion Project (NGEP). ${ }^{11,12}$

Several investigations have been underway to diagnose discharge cathode erosion in the 30-cm NSTAR ion thruster involving Laser-Induced Fluorescence (LIF) measurements, measurement of energetic ions near the DCA, and (concurrent with this investigation) electrostatic probing of the discharge chamber and discharge cathode. ${ }^{13-20}$ High-resolution discharge plasma characterization of the near-DCA region of a 30-cm NSTAR thruster has been accomplished utilizing a high-speed probe positioning system. ${ }^{21-24}$ Mapping the internal plasma structure of the 30$\mathrm{cm}$ ion engine downstream of the DCA permitted the elimination of the potential hill theory as an explanation of the DCA erosion and illustrated a free-standing double layer plasma potential structure. The double layer is aligned with the axial magnetic field near the DCA and forms the transition between the low potential discharge cathode plume and the high potential bulk discharge plasma.

In an attempt to diagnose DCA erosion issues, an investigation of the discharge plasma structure of a $40-\mathrm{cm}$ NEXT ion thruster has been initiated. To the author's knowledge this is the only internal investigation on a NEXT ion thruster to date. The purpose of this experiment is to obtain high spatial resolution plasma potential measurements in the discharge chamber of the $40-\mathrm{cm} \mathrm{NEXT} \mathrm{ion} \mathrm{engine,} \mathrm{focusing} \mathrm{on} \mathrm{the} \mathrm{near-DCA} \mathrm{region.} \mathrm{A}$ secondary probe, located closer to the ion optics, offers additional valuable discharge chamber data. Determination of the discharge plasma environment permits evaluation of the DCA erosion mechanisms and estimation of the NEXT DCA erosion rate.

\section{40-cm NEXT Ion Thruster}

The NEXT ion engine follows the "derated" approach of the NSTAR program to preserve the NSTAR design heritage. This design approach maintains low beam current densities, low component operating temperatures (most importantly the permanent magnets), and reduces operating voltages that can accelerate wear mechanisms. To maintain low beam current densities while increasing throughput, an engine twice the beam area of the NSTAR thruster was designed. Increasing the engine beam diameter from $28-\mathrm{cm}$ (NSTAR) to $40-\mathrm{cm}$ (NEXT) doubles the beam extraction area. The higher beam area provides higher-power capability while maintaining comparable current densities, temperatures, and operating voltages. An input power of 4.7$\mathrm{kW}$ on the NEXT engine operates at the same voltages and beam current density as $2.3-\mathrm{kW}$ on the NSTAR engine. The NEXT engine can therefore be expected to yield the same operating lifetime while producing twice the thrust.

\section{A. NEXT Engine Design}

The major components of the NEXT engine are designed based upon the NSTAR thruster. These include a nonferrous spun-form discharge chamber, comparable discharge and neutralizer hollow cathode designs, similar electrical isolation techniques, analogous flake retention mesh, and dished two-grid ion-optics system. Improvements beyond NSTAR include: improved beam flatness via magnetic field design, a compact propellant isolator, increased beam voltage (up to $1800 \mathrm{~V}$ ), and advanced ion optics design. The discharge and neutralizer cathodes have increased dimensions to accommodate the elevated current required along with some minor modifications. Performance testing of two engineering model thrusters and a laboratory model thruster exhibit peak specific impulse and thrust efficiency ranges of $4060-4090$ seconds and $0.68-0.69$, respectively, at the $6.1 \mathrm{~kW}$ 
power point. ${ }^{25}$ A 2000 hour wear test has been conducted on Engineering Model 1 (EM1) at a thruster input power of $6.9 \mathrm{~kW}$ demonstrating specific impulse, thrust efficiency, and calculated thrust of $4110 \mathrm{~s}, 0.694$, and $237 \mathrm{mN}$ respectively. ${ }^{26} \mathrm{~A}$ long-duration test of an EM thruster at NASA GRC has begun at the time of this publication and is expected to exceed 8000 hours of operation. At this date, the construction of a prototype model thruster is ongoing. ${ }^{27}$

\section{B. Laboratory Model 4 (LM4) 40-cm NEXT Ion Thruster}

The fourth-built, $40-\mathrm{cm}$ laboratory model NEXT ion engine, referred to as LM4, was designed, fabricated, and assembled at NASA GRC. The engine design was modified with the intention of conducting electrostatic probe measurements and future Laser-Induced Fluorescence (LIF) measurements, inside the discharge chamber for normal engine operation with beam extraction. The LM4 variant is functionally equivalent to the NASA NEXT EM design with several incorporated features to facilitate discharge plasma interrogation and LIF characterization. The principal modifications between the LM4 and the EM thrusters include:

- Rotation of the gimbal and ion optics mounting by 45 degrees.

- Fabrication of a purely cylindrical plasma shield to facilitate access to the discharge chamber and reduce the complexity of the discharge plasma containment design.

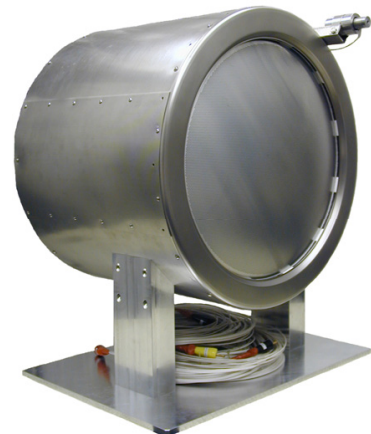

Figure 2. Laboratory model 4 (LM4) 40-cm NEXT ion thruster.

- Anode fabrication from welded stainless steel sheet opposed to the NEXT EM thruster spun stainless steel anode.

- Incorporation of mechanical cathodes (employing machined Macor to isolate the cathode common, cathode heater, and cathode keeper) for the LM4 as opposed to the brazed cathode assemblies of the NEXT EM thrusters.

- Incorporation of a machined stainless steel optics mounting ring assembly instead of the ion optics stiffener ring mounting assembly of the EM's.

- Iso-mica optics spacer and macor tabs used to hold the grids in place and set the grid gap.

- Modification of the high-voltage propellant isolator design.

- Modification of the neutralizer mounting (at 45 degrees).

These design changes have a negligible effect on the operation of LM4 when compared to the 40-cm Engineering Model thrusters (EM's), as verified by magnetic field mappings and engine performance testing. ${ }^{28}$

\section{LM4 Engine Modifications}

Following confirmation of comparable performance to the EM's from characterization testing, the LM4 anode is modified for electrostatic probe access to the discharge chamber via slots in the side of the anode, shown in Figure 3. Slots are cut into the anode side and top for probe access and alignment of the probe to the discharge cathode assembly, respectively. Flanges are mounted to the slots permitting axial motion perpendicular to the flange opening and allowing easy transition between probe interrogation hardware and future LIF windows. The LM4 modifications and added hardware components are illustrated in Figure 3. 

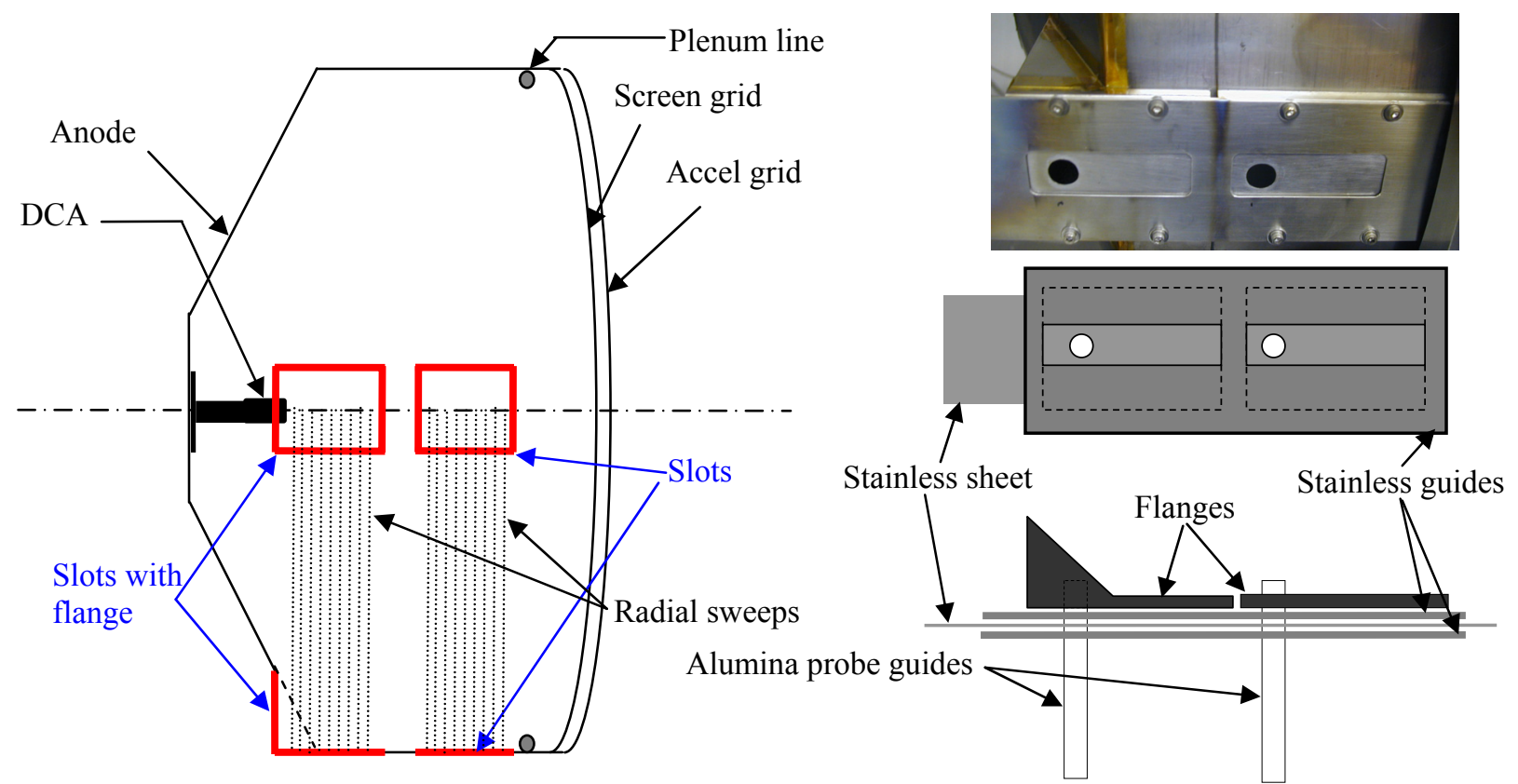

Figure 3. LM4 discharge interrogation modifications. Schematic of the slots and mounting flanges on anode (left). The discharge plasma containment hardware is illustrated on the right.

\section{Experimental Apparatus}

\section{A. Vacuum Testing Facility}

The LM4 discharge chamber investigations are conducted in the Plasmadynamics and Electric Propulsion Laboratory (PEPL) cylindrical 6-m-diameter by 9-m-long stainless steel-clad Large Vacuum Test Facility (LVTF). With seven cryopumps activated, surrounded by liquid nitrogen cooled baffles, the LVTF maximum pumping speed is $240,000 \mathrm{l} / \mathrm{s}$ on xenon $(500,000 \mathrm{l} / \mathrm{s}$ on air). Pressure measurements, from a Varian model UHV-24 nude ion gauge with a Varian UHV senTorr vacuum gauge controller mounted on the LVTF wall, are corrected for xenon using the known base pressure on air, the indicated gauge pressure, and a correction factor of 2.87 for xenon according to, ${ }^{29}$

$$
P_{c}=\frac{P_{i}-P_{b}}{2.87}+P_{b}
$$

The LVTF is operated with either four or seven cryopumps depending upon ion thruster operating condition. With four cryopumps, the facility pumping speed is $140,000 \mathrm{l} / \mathrm{s}$ on xenon with a base pressure typically $4 \times 10^{-7}$ Torr. The LVTF can maintain a pressure in the low $10^{-6}$ Torr range during operation of the LM4 at low-to-mid power with the four cryopumps activated. To reduce the ingested flow into the discharge chamber, the LM4 testing is conducted with four cryopumps for low-to-mid power and with seven cryopumps for higher power. With seven cryopumps activated, the LVTF base pressure is $2 \times 10^{-7}$ Torr. At the LM4 highest power condition permissible, the corrected background pressure is $2.8 \times 10^{-6}$ Torr for a total xenon flow rate of $5 \mathrm{mg} / \mathrm{s}$.

\section{B. High-speed Probe Positioning System (HARP)}

A linear motor assembly provides accurate direct linear motion of the probe with minimal discharge cathode plume residence times. The HARP system, shown in Figure 4, is a three-phase Trilogy 210 brushless dc servo motor consisting of a linear "U"-shaped magnet track and a "T"-shaped coil moving on a set of linear tracks. The linear encoder provides positioning resolution to $5 \mu \mathrm{m} .^{30}$ A Pacific Scientific SC950 digital, brushless servo drive controls the motor. The HARP is a linear table with a $559 \mathrm{~mm}$ stroke length. The HARP is capable of moving small probes at speeds above $250 \mathrm{~cm} / \mathrm{s}$ with acceleration rates above $7 \mathrm{~g}$ 's. The entire HARP table is enclosed in a stainless steel 
shroud with a graphite outer skin. Residence times of the probe inside the discharge cathode plume are kept under 100 msec to minimize probe heating and discharge plasma perturbation. The HARP system was initially designed for internal discharge channel electrostatic probe measurements on Hall thrusters. ${ }^{14,30-34}$ The HARP system is minimally modified for $30-\mathrm{cm}$ NSTAR discharge chamber characterization and the near DCA 40-cm NEXT discharge plasma characterization. ${ }^{21-24}$ The primary modifications include the probe mounting on-axis with the HARP and optimization of the control variables to achieve the desired sweep for trajectory given the HARP velocity and acceleration requirements.

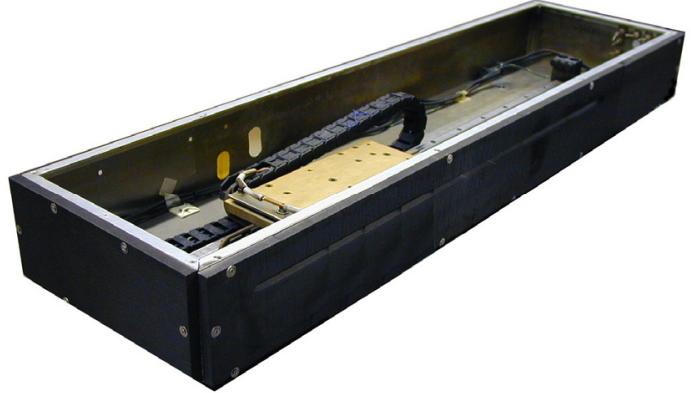

Figure 4. High-speed Axial Reciprocating Probe (HARP) positioning system.

\section{Axial Movement of Probe}

A single-axis Aerotech ATS62150 linear ball screw translation table provides axial movement of the thruster relative to the probe. The Aerotech table has a travel length of $1.5 \mathrm{~m}$ with an accuracy of $\pm 2.5 \mu \mathrm{m}$. A Renco RCM21 encoder provides precision measurement of the position of the thruster with a resolution of $5 \mu \mathrm{m}$ and a frequency response of $200 \mathrm{kHz}$. The orientation of hardware and probes is illustrated in Figure 5. Two staggered electrostatic probes are inserted into the LM4 discharge plasma in the radial direction. The upstream probe characterizes the near-DCA region, while the downstream probe characterizes the near-optics region. The near-DCA mapping begins $\sim 1.5 \mathrm{~mm}$ downstream of the discharge keeper face with an axial resolution of $1 \mathrm{~mm}$. Each probe is activated individually, with the dormant probe floating. When actuated, the probe extends to the thruster centerline then returns to the starting location recessed inside the translating alumina tube. When not in use, the probes are recessed in the guiding alumina tube protecting the probes and reducing probe perturbations on the LM4 thruster operation.

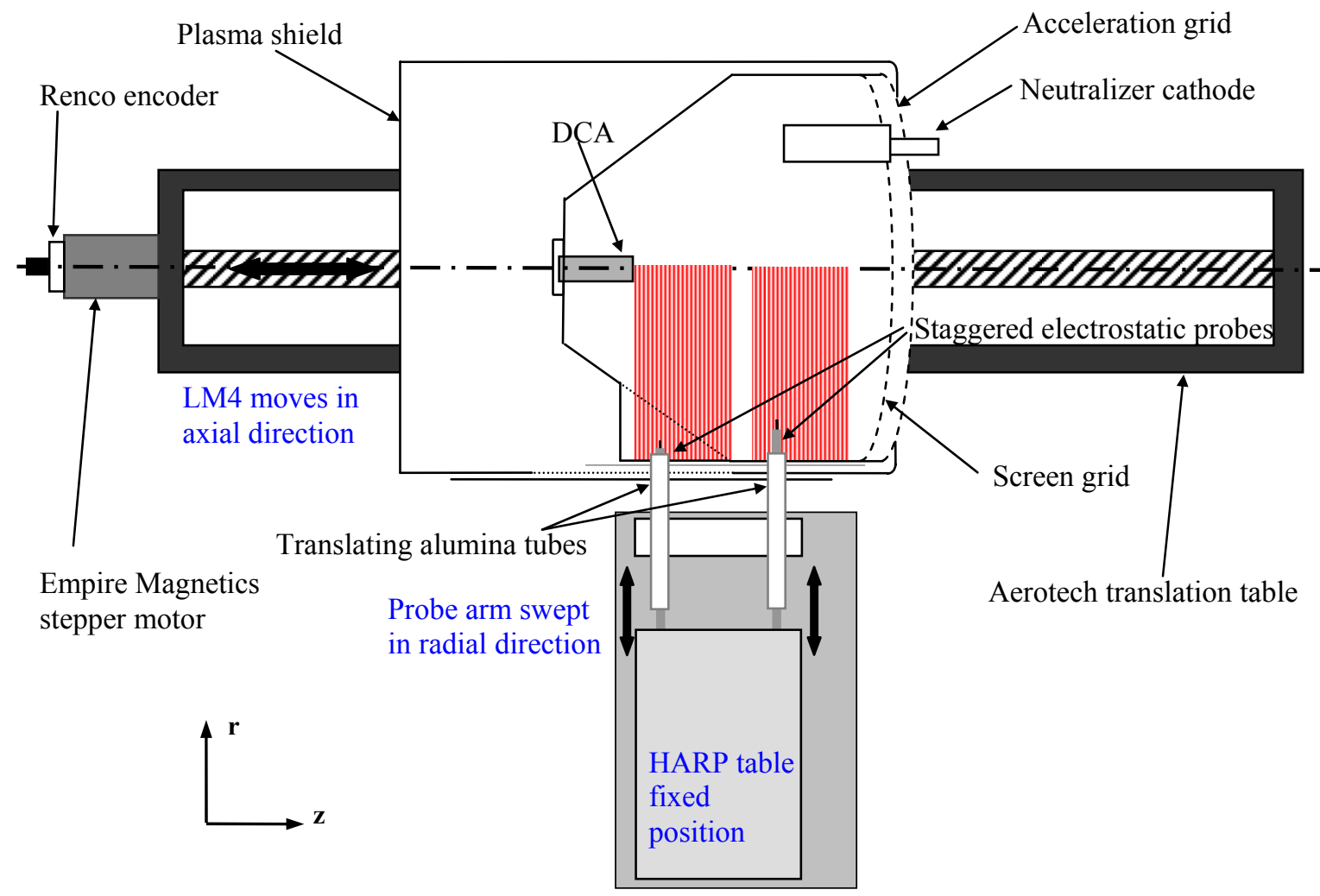

Figure 5. LM4 and HARP orientation with the translating table permitting axial movement. 


\section{Floating Emissive Probe Diagnostic}

Electron emission from "hot" electrostatic probes provides a method to directly measure the local plasma potential. This measurement resolves many problems encountered with interpretation of the "knee" in the I-V characteristic used to estimate the plasma potential for single Langmuir probes. Langmuir probe I-V characteristics are complicated by probe geometry, magnetic field effects, the presence of flowing plasma, and ionization near the probe. ${ }^{35}$ Emitting probes offer an alternative technique to determine the plasma potential that is insensitive to plasma flow, plasma density, and electron temperature. Furthermore, emissive probes provide a means to accurately measure the local plasma potential in fluctuating plasma environments.

\section{A. Theory of Operation}

The floating emissive probe operates under a simple principle yielding direct measurement of the local plasma potential without the need for a bias voltage sweep or extensive data analysis. The theory of the floating emissive probe is well established. $^{35-39}$ Current is applied through a filament that is inserted into the plasma at the point of interest. As the filament heats up, electrons are thermionically emitted from the filament. In theory, when heated sufficiently (to the saturation current), the emitted electrons neutralize the sheath around the probe tip allowing the probe (and probe circuitry) to float at the local plasma potential. In reality,

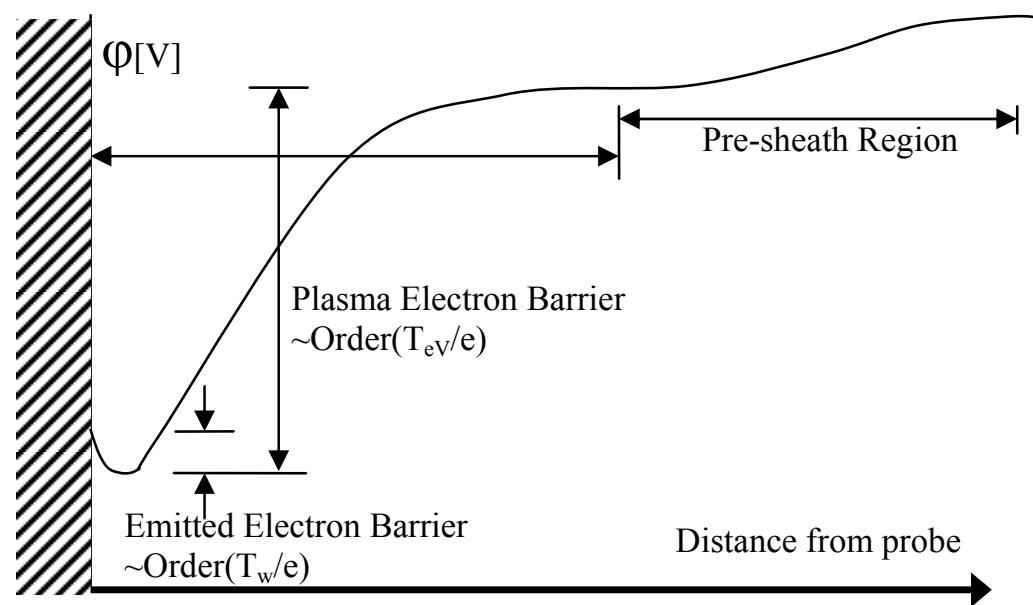
Figure 6. Schematic of the potential distribution in a double sheath surrounding an emitting probe

for the floating probe in strong emission, the space-charge limit creates a double sheath because of the excess of slow electrons emitted near the probe surface, illustrated in Figure 6. The double sheath reflects the thermionically emitted electrons back to the probe surface and some of the Maxwellian plasma electrons back to the plasma. The high-energy Maxwellian tail electrons from the plasma are still able to reach the probe. The disparity in energies of the Maxwellian and thermionically emitted electron populations dictates that the maximum emitted current cannot be sufficient to compensate for the collected current because the plasma electrons have much higher velocities. This leads to an emissive probe floating potential that is less than the true local plasma potential.

The structure surrounding the emissive probe can be broken into pre-sheath and collector sheath regions. The pre-sheath spatial dimension is on the order of the mean free path in the plasma, while the collector sheath is on the order of the Debye length. The magnitude of the potential barrier to the emitted electrons is on the order of $\mathrm{T}_{\mathrm{w}} / \mathrm{e}$, where $T_{w}$ is the filament temperature. The potential barrier preventing plasma electrons from reaching the probe is on the order of $T_{e} / e$. As a result, the emissive probe will float at a potential $\left(T_{e}-T_{w}\right) / e$ less than the true plasma potential. Since $T_{e}>>T_{w}$ this is approximated as $T_{e} / e$. The presence of positive ions helps to cancel the space charge reducing the difference between floating probe potential and plasma potential to a fraction of $T_{e}$.

\section{B. Emissive Probe Filament}

The emitting portion of the probe, shown in Figure 7, consists of $0.13 \mathrm{~mm}$ diameter tungsten wire bent to form a closed loop roughly $1.2 \mathrm{~mm}$ in diameter. The "double tier" design of the emissive probe tip reduces the amount of blockage mass that is inserted into the discharge cathode plume. The probe is oriented such that the plane of the loop of the probe filament is perpendicular to the thruster axial direction. This allows the maximum axial resolution and bodes well with the axisymmetric nature of the discharge chamber and discharge cathode plume. Several probe tips are used during this investigation, due filament failure when operated in strong emission at the high HARP accelerations (up to $7 \mathrm{~g}$ 's), each requiring a slightly different saturation heater current. For the strong emission necessary to neutralize the probe sheath, the tungsten filament is heated by the dc supply current passing through the filament until it is close to the tungsten melting temperature $(3695 \mathrm{~K})$. This limits the lifetime of the probe in the harsh discharge cathode plume environment 


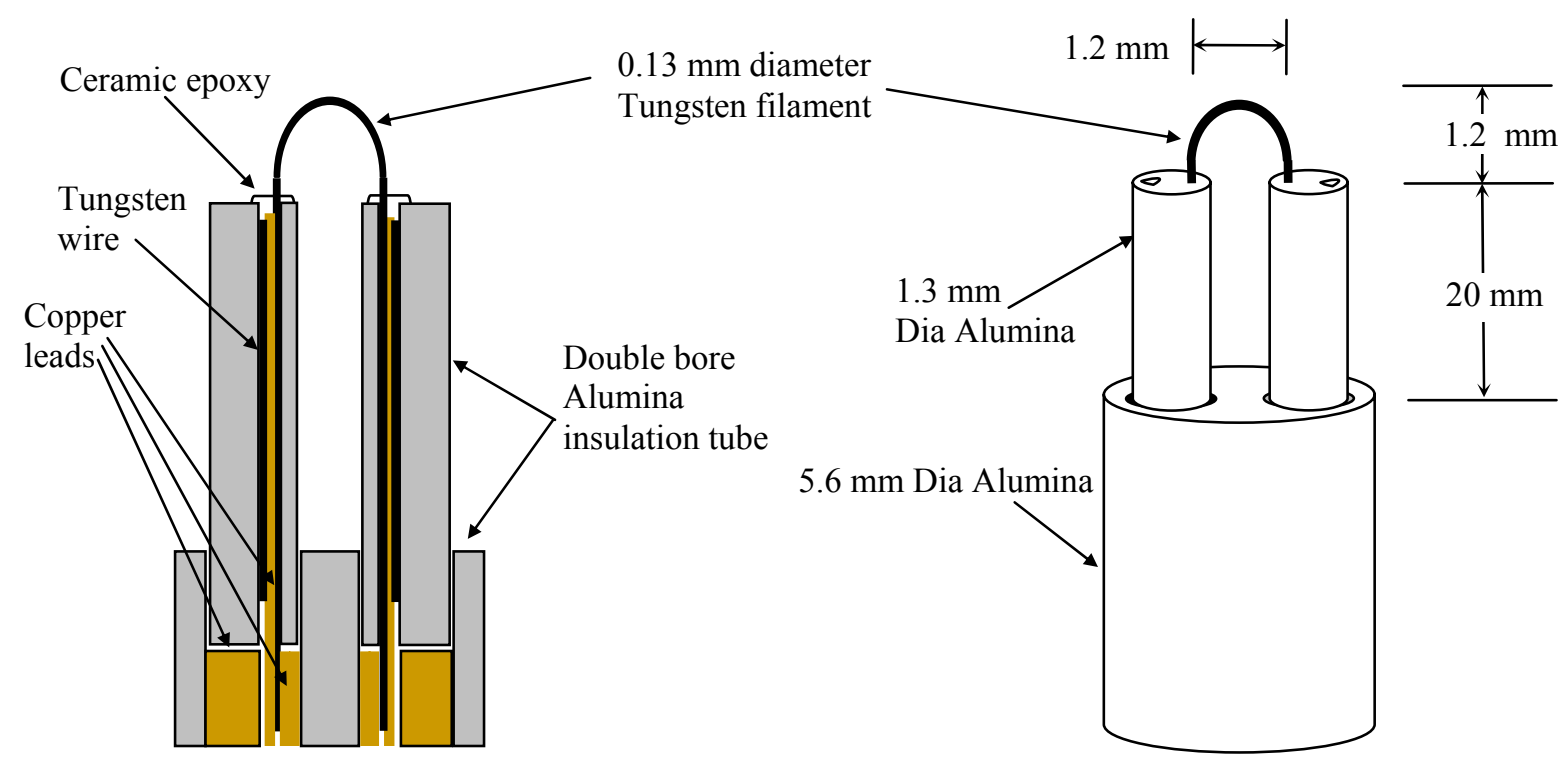

Figure 7. Floating emissive probe tip design illustrating the components and physical dimensions.

\section{Emissive Probe Circuit and Analysis}

The emissive probe circuit, illustrated in Figure 8, consists of the emissive probe, a dc power supply to heat the filament, an isolation transformer to isolate the power supply from ground, and two AD210 isolation amplifiers to record both the emitting probe potential and the voltage drop across the filament. The probe is swept in the radial direction at discrete axial locations. For each sweep, the probe position, probe floating potential (plasma potential), and filament voltage drop are recorded.

All of the plasma potential measurements are made with respect to the discharge cathode common and not the facility ground. Both the "high" and "low" side floating potentials, of the power supply, are recorded indicating the uncertainty of the measurement. The probe floating potential will always be a fraction of the electron temperature less than the true local plasma potential. For ion thrusters, the electron temperatures are fairly constant ranging from $2-5$ $\mathrm{eV}$ in the bulk discharge. . $2,24,40^{2}$

The LM4 ion engine is throttled to the desired operating condition and allowed sufficient time ( $\sim 1 / 2$ hour) to reach steady operation. In order for the probe floating potential to approach the true plasma potential, adequate heater current must be applied to the filament to neutralize the probe sheath. The correct heater current is determined by taking several preliminary sweeps at the zero axial position and observing

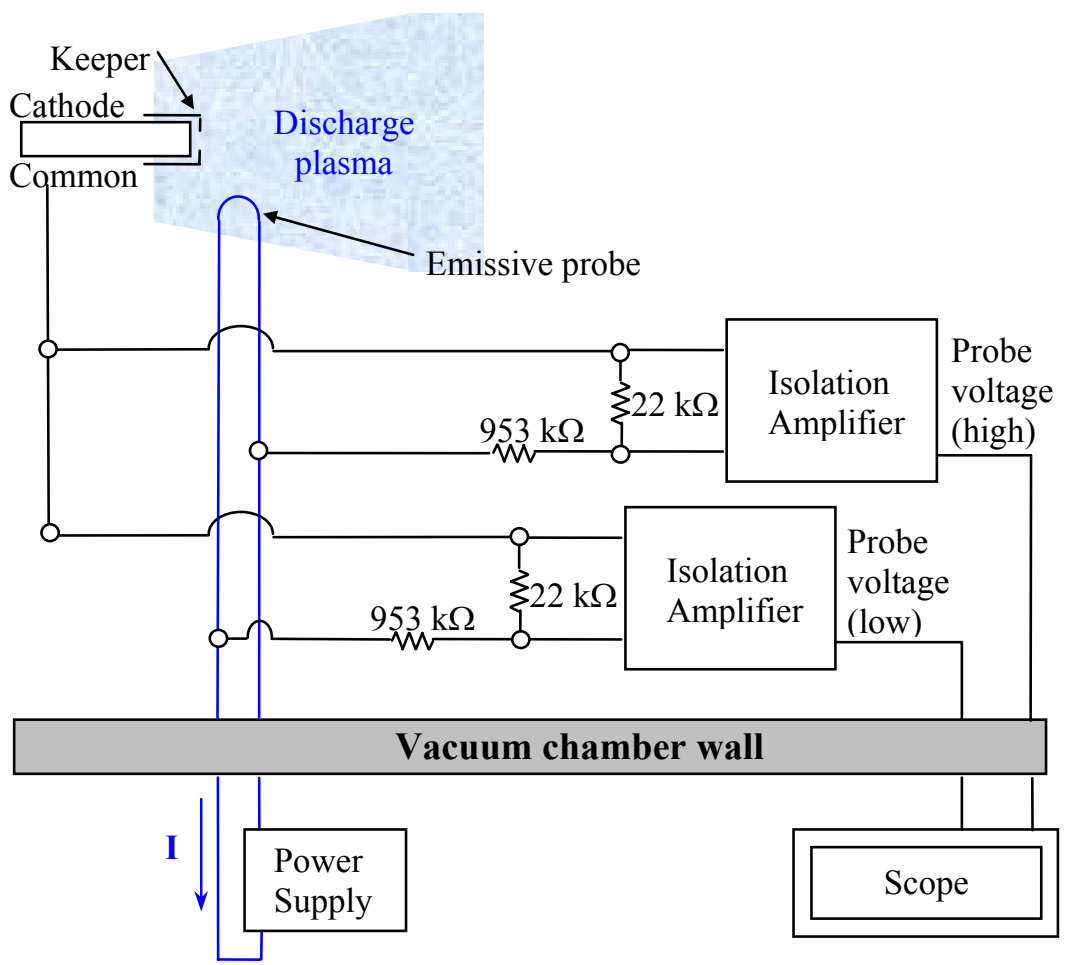

Figure 8. Floating emissive probe circuit and electrical diagram. when the probe potential traces saturate inside the discharge cathode plume. Once a sufficient heater current is determined, the emissive probe current is held at this value over the entire data collection domain. Problems setting the heater current occur for high-power thruster operation. If the heater current is set for the bulk plasma region, 
excessive filament heating occurs in the DCA plume resulting in rapid filament failure. Conversely, if the heater current is set for the discharge cathode plume, the probe will have insufficient heater current in the bulk discharge region. Accurate measurement of the near-DCA plasma is the primary area of interest and therefore the heater current will be set to accurately measure this region. The bulk discharge measurements at high-power thruster operation are reported, but are lower than the true plasma potential in these locations. A more accurate mapping of the bulk discharge plasma and near-cusp anode regions could be performed separately, however, were beyond the scope of this investigation.

\section{Magnetic Field Effects}

The presence of large magnetic fields and large density gradients can increase the problems associated with space-charge limited emission. In magnetized plasmas, the emitted electrons follow the magnetic field rather than expanding away from the probe in all directions, increasing the disparity between the potential of the emitting probe and the actual local plasma potential. Additional space-charge effects due to the magnetic field can be avoided by sizing the probe such that the filament diameter, that is the diameter of the tungsten wire and not the loop diameter, is much less than the electron gyroradius. This condition has been shown by Hershkowitz to be equivalent to the following equation: ${ }^{35}$

$$
B<<\frac{4.8 \sqrt{T_{e V}}}{(d / 10)}
$$

In Eq. $4, \mathrm{~T}_{\mathrm{eV}}$ is in $\mathrm{eV}, \mathrm{d}$ is the emitting filament diameter in $\mathrm{mm}$, and $\mathrm{B}$ is the magnetic field in Gauss. For a filament diameter of $0.13 \mathrm{~mm}$ and electron temperatures inside the discharge chambers ranging from $2-7 \mathrm{eV}$, over all operating conditions investigate, the Hershkowitz equation yields the restriction that $\mathrm{B}<<650 \mathrm{G}$. The maximum magnetic field magnitude over the range of spatial locations investigated in the discharge chamber of the LM4 engine is on the order of a few hundred Gauss occurring near the magnetic cusp regions at the anode. Near the DCA, the primary region of interest, the magnetic field strength is on the order of several tens of Gauss at the exit plane of the discharge cathode and decreases with increasing axial and radial distances from the centerline DCA exit plane. Even for the worst case, close to the magnetic cusps, the Hershkowitz criterion is maintained.

\section{E. Error Analysis}

There are several sources of error in the floating emissive probe diagnostic technique. Noise is reduced as much as possible by using high-voltage SHV coaxial cables for the entire circuit, both inside and outside of the vacuum chamber. Isolated feedthroughs permit a common grounding point for all circuit components, eliminating noise pick-up through ground loops. The non-ideal floating power supply introduces the possibility of leakage current to ground when the probe and dc supply float at high-potential. The result of appreciable leakage current is the probe floating at a value less than the true plasma potential. To determine the effect of the leakage current, the measured plasma potential near the anode is compared to the true anode potential. Examination of the plasma potential contours for low-to-mid power thruster operation illustrate that near the anode the measured plasma potential is equal to or a few volts above anode potential. This indicates that there is no appreciable leakage current. The perturbation of the discharge current by the probe insertion is recorded throughout the test. As expected the maximum perturbation occurrs at the closest axial position on centerline. The temporary perturbation spike in discharge current is at most $10 \%$ of the nominal value. Typical perturbations were $5-10 \%$ of the nominal discharge current. Outside of the discharge cathode plume region, no perturbation is detectable.

Plasma potential measurement, with heater current through the filament, leads to a voltage drop across the filament. This voltage drop adds to the uncertainty in the measured value. The voltage drop is recorded during testing and is approximately $3 \mathrm{~V}$, leading to an uncertainty of \pm 1.5 volts from the averaged floating potential. The effects of the leakage current and voltage drop contribute to an overall shift in absolute magnitude of plasma potential measurement, however, the relative potential measurements unaffected. Due to space-charge effects, the electron current from the highly emissive probe is limited, and the true plasma potential will be underpredicted. Thus the emissive probe measurement gives rise to an error on the order of a fraction of $T_{e} / e^{36,41,42}$ Given the electron temperatures measured with the Langmuir probes, the floating potentials can be corrected. The electron temperatures vary from roughly $2-5 \mathrm{eV}$ in the near DCA domain. ${ }^{40}$ 
Combining the emissive probe voltage drop and space-charge effect errors the apparent plasma potential from the emissive probe diagnostic setup is accurate to $+2 /-3 \mathrm{~V}$ of the high supply side floating potential.

\section{F. LM4 Operating Conditions Investigated}

The LM4 thruster emissive probe investigation is performed over a variety of thruster operating conditions listed in Table 1. The engine operation is limited for high-power operation by the beam and discharge power supplies. The investigation covers a range of conditions from low-to-mid power. In addition to the nominal operation with beam extraction, the thruster is operated with discharge only (no beam extraction) and with the discharge keeper shorted to discharge cathode common. The thruster operating condition naming conventions are: floating emissive probe (FEP) nominal Thruster Operating Conditions (TOC Levels), Discharge only Level (DL), and reference NEXT selfassigned Throttling Levels (TH Levels).

Table 1: LM4 floating emissive probe (FEP) nominal Thruster Operating Conditions (TOC Levels), Discharge only Level (DL), and reference NEXT self-assigned Throttling Levels (TH Levels).

\begin{tabular}{|c|c|c|c|c|c|c|c|c|c|c|c|c|c|c|c|}
\hline & $\mathrm{TH}$ & Vs & $\mathrm{Jb}$ & $\mathrm{Va}$ & $\mathrm{Ja}$ & Vdc & Jdc & Vnk & Jnk & $\begin{array}{l}\text { Main } \\
\text { Flow }\end{array}$ & $\begin{array}{l}\text { D.C. } \\
\text { Flow }\end{array}$ & $\begin{array}{l}\text { Neut } \\
\text { Flow }\end{array}$ & $\begin{array}{l}\text { Vck- } \\
\text { cc }\end{array}$ & $\mathrm{Vg}$ & Pressure \\
\hline & Level & [v] & {$[\mathrm{A}]$} & [V] & {$[\mathrm{mA}]$} & [V] & {$[\mathrm{A}]$} & [V] & {$[\mathrm{A}]$} & [sccm] & {$[\mathrm{sccm}]$} & [sccm] & [V] & [V] & [Torr] \\
\hline \multirow{7}{*}{ 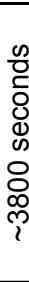 } & TH 34 & 1567 & 3.10 & -210.0 & 10.50 & - & 17.68 & - & 3.00 & 43.47 & 4.54 & 4.01 & - & 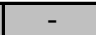 & 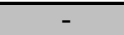 \\
\hline & FEP TOC 34a' & 1501 & 3.10 & -210.1 & 14.19 & 23.71 & 17.54 & 12.85 & 3.00 & 43.5 & 4.54 & 3.99 & 4.63 & -12.31 & $2.9 \mathrm{E}-06$ \\
\hline & FEP TOC 34b' & 1450 & 3.00 & -210.1 & 18.04 & 23.30 & 17.27 & 12.20 & 3.00 & 40.5 & 4.41 & 4.36 & 4.54 & -11.76 & $4.5 \mathrm{E}-06$ \\
\hline & $\begin{array}{l}\text { FEP TOC 34' } \\
\text { CK-CC shorted }\end{array}$ & 1455 & 3.00 & -210.1 & 18.05 & 23.22 & 17.23 & 12.32 & 3.00 & 40.5 & 4.41 & 4.36 & - & -11.85 & $4.5 \mathrm{E}-06$ \\
\hline & TH 20 & 1567 & 2.00 & -210.0 & 6.80 & - & 14.12 & - & 3.00 & 25.79 & 3.87 & 2.50 & - & - & - \\
\hline & FEP TOC 20a' & 1449 & 2.00 & \begin{tabular}{|l|}
-210.1 \\
\end{tabular} & 8.70 & 24.30 & 13.75 & 12.89 & 3.00 & 25.0 & 3.87 & 2.46 & 2.06 & -11.47 & $3.2 \mathrm{E}-06$ \\
\hline & FEP TOC 20b' & 1466 & 2.00 & -210.2 & 8.37 & 24.57 & 14.23 & 13.04 & 3.00 & 24.4 & 3.83 & 2.46 & 1.58 & -11.84 & $3.2 \mathrm{E}-06$ \\
\hline \multirow{11}{*}{ 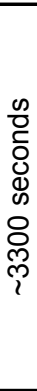 } & & & & & & & & & & & & & & & \\
\hline & TH 32 & 179 & 3.10 & -200.0 & 0.50 & - & 18.63 & - & 3.00 & 43.47 & 4.54 & 4.01 & - & - & - \\
\hline & FEP TOC $32 a$ & 1180 & 3.11 & -200.2 & 14.63 & 23.97 & 18.04 & 12.97 & 3.00 & 43.5 & 4.54 & 3.99 & 4.65 & -12.38 & $2.9 \mathrm{E}-06$ \\
\hline & FEP TOC 32b & 1179 & 3.00 & -200.1 & 18.61 & 23.37 & 17.44 & 11.79 & 3.00 & 42.5 & 4.48 & 4.36 & 5.00 & -11.61 & $4.5 \mathrm{E}-06$ \\
\hline & TH 18 & 1179 & 2.00 & -200.0 & 6.80 & - & 14.72 & - & 3.00 & 25.79 & 3.87 & 2.50 & 0.0 & - & - \\
\hline & FEP TOC 18 & 1179 & 2.00 & -200.1 & 8.80 & 24.66 & 13.89 & 12.74 & 3.00 & 25.0 & 3.87 & 2.46 & 2.33 & -11.18 & $3.2 \mathrm{E}-06$ \\
\hline & TH 8 & 1179 & 1.20 & -200.0 & 4.10 & - & 8.83 & - & 3.00 & 14.23 & 3.57 & 3.00 & - & - & - \\
\hline & FEP TOC 8a & 1179 & 1.20 & -200.2 & 4.29 & 26.01 & 8.75 & 13.20 & 3.00 & 14.6 & 3.56 & 3.09 & 3.30 & -11.16 & $2.4 \mathrm{E}-06$ \\
\hline & FEP TOC $8 b$ & 1179 & 1.20 & -200.2 & 3.42 & 27.05 & 9.12 & \begin{tabular}{|l|}
14.51 \\
\end{tabular} & 3.00 & 14.7 & 3.61 & 3.00 & 3.26 & -10.47 & $1.6 \mathrm{E}-06$ \\
\hline & \begin{tabular}{|l|} 
FEP TOC 8 \\
CK-CC shorted
\end{tabular} & 1179 & 1.20 & -200.1 & 4.38 & 25.93 & 8.70 & 13.14 & 3.00 & 14.6 & 3.51 & 3.09 & - & -10.97 & 2.4E-06 \\
\hline & FEP DL 8 & - & - & - & 12.28 & 23.20 & 8.70 & 14.64 & 3.00 & 14.6 & 3.48 & 3.09 & 7.07 & -1.53 & 2.4E-06 \\
\hline & & & & & & & & & & & & & & & \\
\hline \multirow{6}{*}{$\begin{array}{l}\bar{\phi} \\
0 \\
0 \\
0 \\
\vdots \\
\vdots\end{array}$} & TH 3 & 650 & 1.20 & -144.0 & 4.10 & - & 9.54 & - & 3.00 & 14.23 & 3.57 & 3.00 & - & - & - \\
\hline & FEP TOC 3a & 650 & 1.20 & -144.1 & 4.72 & 26.25 & 9.77 & 13.36 & 3.00 & 14.6 & 3.56 & 3.09 & 3.18 & -11.16 & $2.4 \mathrm{E}-06$ \\
\hline & FEP TOC $3 b$ & 650 & 1.20 & -144.0 & 3.55 & 27.03 & 9.58 & 14.74 & 3.00 & 14.6 & 3.63 & 3.00 & 3.93 & -10.13 & $1.5 \mathrm{E}-06$ \\
\hline & TH 0 & 275 & 1.00 & -500.0 & 3.40 & - & 7.99 & - & 3.00 & 12.32 & 3.52 & 3.00 & - & - & - \\
\hline & FEP TOC 0a & 275 & 1.00 & -500.0 & 3.53 & 26.40 & 7.80 & 13.72 & 3.00 & 12.4 & 3.49 & 3.09 & 4.65 & -11.32 & $2.2 \mathrm{E}-06$ \\
\hline & FEP TOC Ob & 275 & 1.00 & -500.0 & 3.41 & 27.10 & 7.95 & 15.15 & 3.00 & 12.3 & 3.52 & 3.00 & 5.32 & -9.79 & $1.4 \mathrm{E}-06$ \\
\hline
\end{tabular}

\section{Results}

Detailed plasma potential mappings are presented over a wide range of operating conditions for the LM4 thruster. 54 two-dimensional mappings are available, though only the relevant results are discussed. A complete display of all the emissive probe data can be found in Reference 28. The magnetic streamlines, from measured magnetic field data for the LM4 thruster, are included in the contour images to aid in their interpretation. For the emissive probe to accurately measure the local plasma potential, sufficient heater current must be applied. This is non-trivial because of the two distinct regions of interrogation (high-density cathode plume and low-density bulk discharge plasma).

Since this investigation relates to near-DCA erosion mechanisms, the emissive probe heater current is set for this region and the bulk discharge potentials are underestimated. The effects of this routine are not evident at the low 
power settings where the discharge current is low. However, the effects become more pronounced as the engine is throttled up to higher power and the increased discharge current substantially heats the probe filament. For the high power thruster conditions, the plasma potential outside the plume are shifted to match the plasma potentials of the downstream plasma in order to give a rough estimate of the bulk plasma environment. These contours are less accurate and may not accurately characterize all of the features of the bulk discharge plasma. Near the anode for the insufficient heater setting, the plasma potential dropped considerably due to the low number densities and therefore that data is omitted. The shifted data is indicated in the contour image caption.

Insufficient heater current in the bulk discharge plasma, at the higher power settings, complicates the comparison of bulk plasma potentials as the engine is throttled, though trends are evident. The plasma potential mappings indicate a slight decrease in bulk plasma potentials as the engine is throttled to higher power. The bulk discharge chamber decrease of a few volts coincides with the decreased discharge voltage at the higher power operating conditions documented in Table 1. This data indicates that there is not be a significant shift in bulk plasma potentials without a corresponding change in discharge voltage. In addition to the data presented here, an investigation of a 30$\mathrm{cm}$ NSTAR ion thruster confirmed this conclusion. ${ }^{23}$ The bulk discharge plasma potentials are on the order of the discharge voltage and increase to 3 or 4 volts above the discharge voltage near the anode inter-cusp regions. A rough inspection of the cathode plume structures illustrates no noticeable change over the operating conditions investigated, though a closer examination of the near-DCA region will follow.

\section{A. Bulk Discharge Chamber Contours}

The shapes of the plasma potential contours for the entire collection domain are illustrated in Figures 9 - 14. The actual LM4 magnetic field streamlines are reproduced on the contour images to assist in the discussion. The magnetic field effectively confines electrons to the field lines resulting in increased plasma potentials in regions between magnetic cusps. The results of the two staggered probes occasionally display some slight mismatch due to differences in probes and heater current settings. Some "streaking" is evident in the radial direction due to engine recycles (momentary shorting between ion optic grids) that affects the probe heating and therefore floating potential. The only noticeable change in contours with increasing power is the shift down in bulk discharge plasma corresponding to the decrease in discharge voltage. Some scatter is evident in the unsmoothed data.

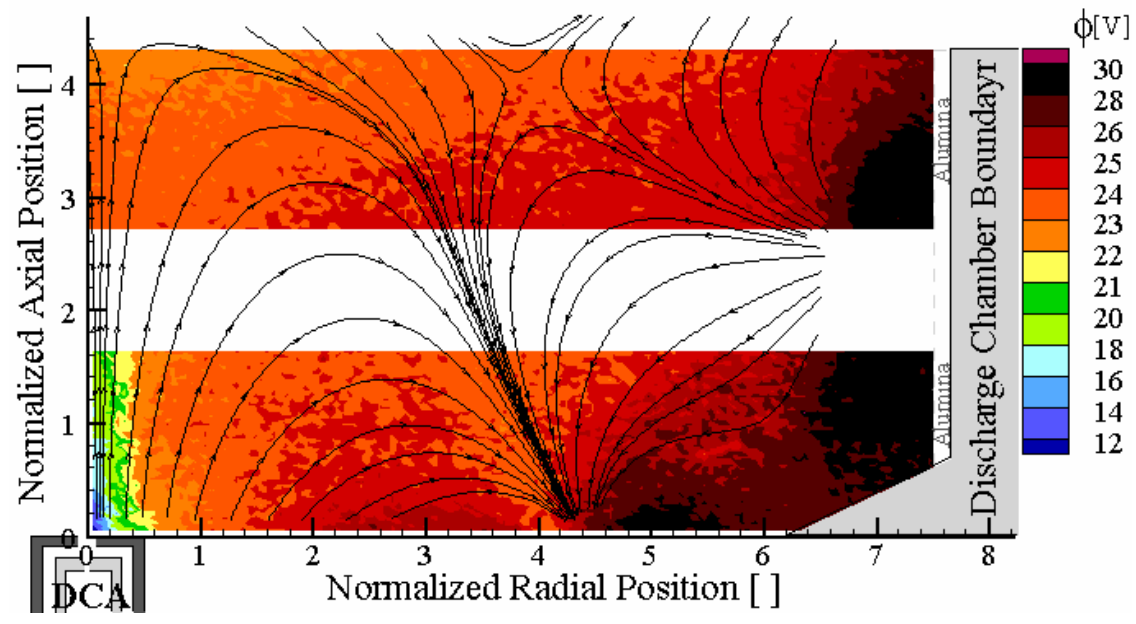

Figure 9. LM4 floating emissive probe plasma potential mapping for FEP TOC 0a $\left(V_{s}=275 \mathrm{~V}, J_{b}=1.00 A\right)$. 


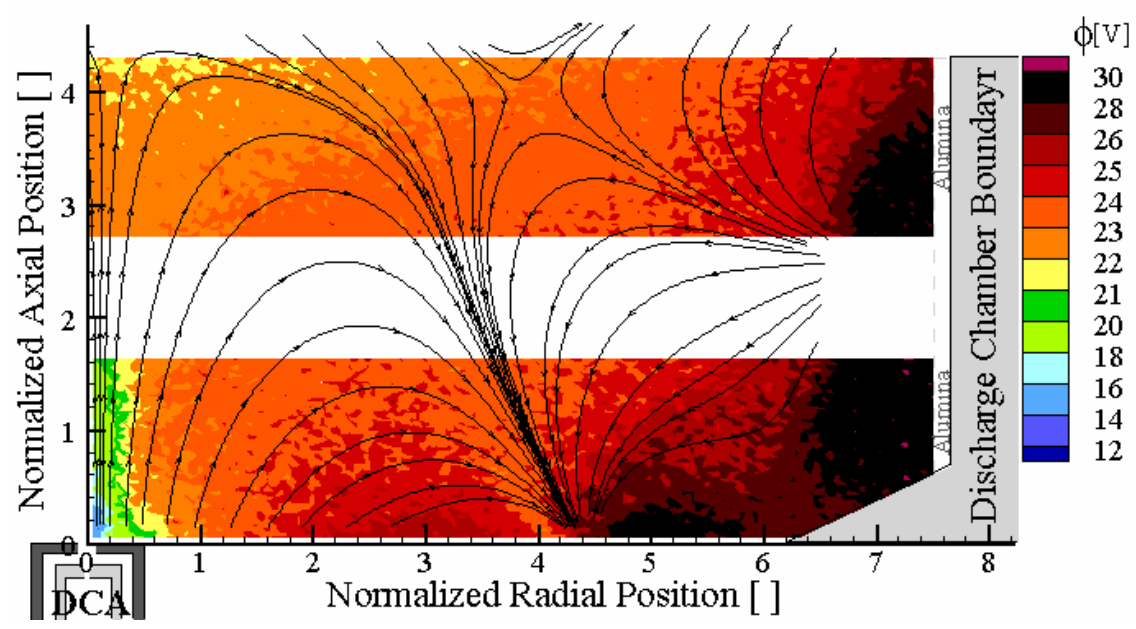

Figure 10. LM4 floating emissive probe plasma potential mapping for FEP TOC 3a $\left(650 \mathrm{~V}, \mathrm{~J}_{\mathrm{b}}=1.20 \mathrm{~A}\right)$.

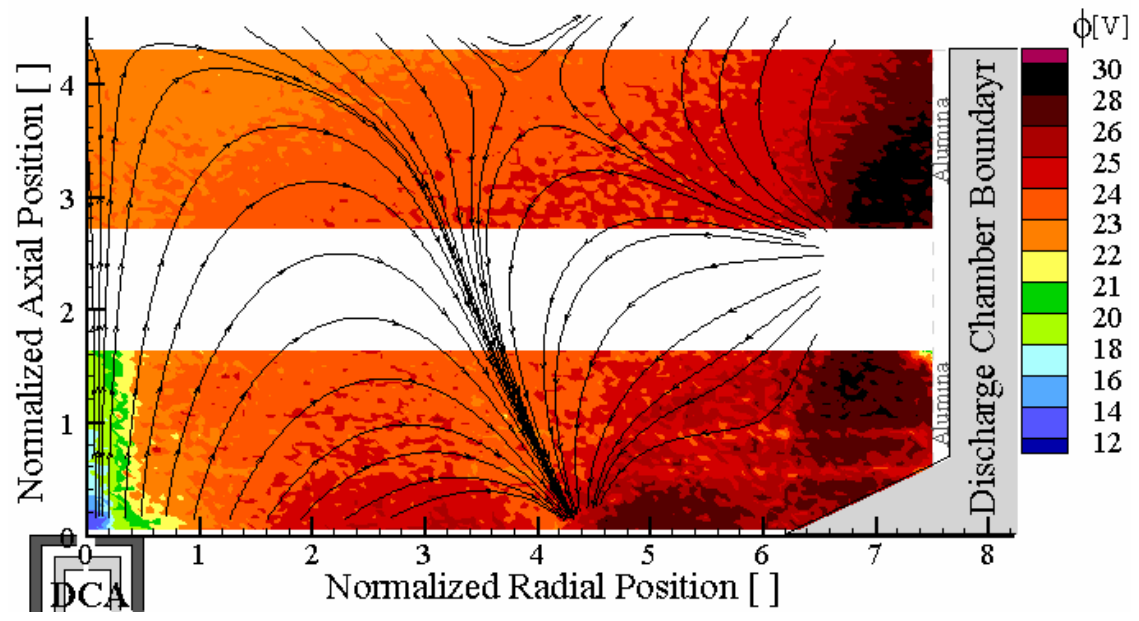

Figure 11. LM4 floating emissive probe plasma potential mapping for FEP TOC 8a $\left(V_{s}=1179 \mathrm{~V}, J_{b}=1.20 A\right)$.

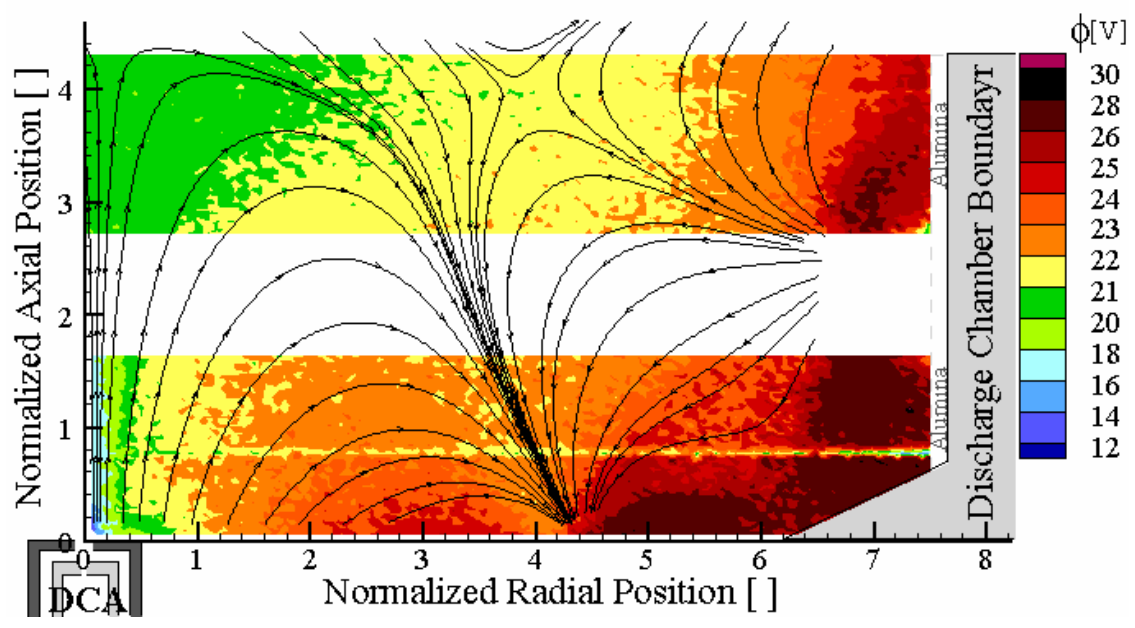

Figure 12. LM4 floating emissive probe plasma potential mapping for FEP TOC $18\left(\mathrm{~V}_{\mathrm{s}}=1179 \mathrm{~V}, \mathrm{~J}_{\mathrm{b}}=2.00 \mathrm{~A}\right)$. 


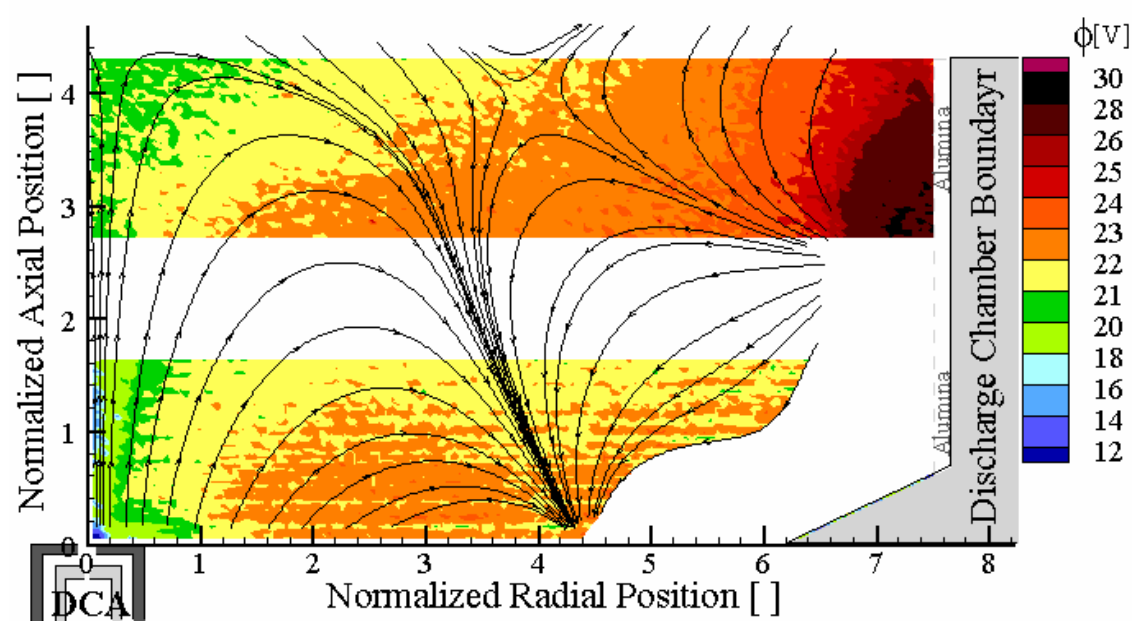

Figure 13. LM4 floating emissive probe plasma potential mapping for FEP TOC $20 b^{\prime}\left(V_{s}=1466 \mathrm{~V}, J_{b}=\right.$ 2.00A). Near-DCA probe potential in the bulk discharge is shifted by 4 volts.

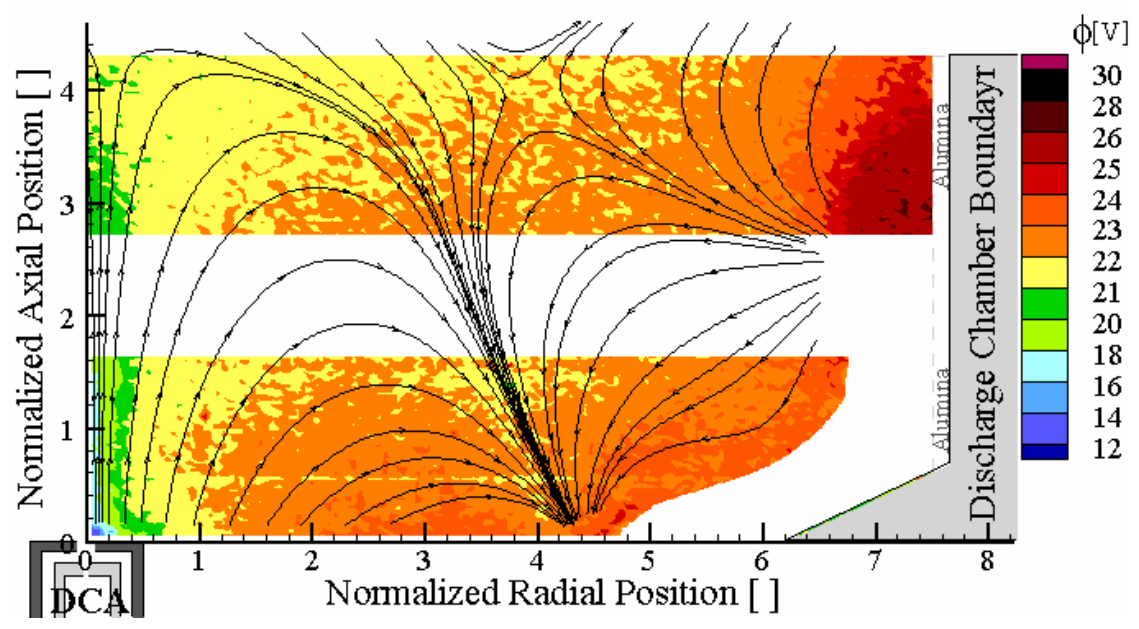

Figure 14. LM4 floating emissive probe plasma potential mapping for FEP TOC 32a $\left(V_{s}=1180 \mathrm{~V}, J_{b}=\right.$ 3.11A). Near-DCA probe potential in the bulk discharge is shifted by 4 volts.

Previous $30-\mathrm{cm}$ ion thruster testing indicated that shorting the discharge cathode keeper to discharge cathode common had no effect outside of the keeper sheath ${ }^{22,23}$. This conclusion is supported by the LM4 results which illustrate negligible differences in the plasma structure when the keeper is shorted to common. These results have been omitted. The lack of beam extraction results in a shift of the bulk discharge plasma equivalent to the shift of the discharge voltage as the beam is not extracted, but the mass flow rates maintained. This shift occurs across the entire interrogation region, including the high-potential inter-cusp regions.

\section{B. Near DCA Plasma Potential Contours}

A closer examination of the plasma potentials near the discharge cathode assembly facilitates evaluation of the formation of high-energy ions near the DCA. Figures 15-18 illustrate that the plasma potentials do not vary noticeably as the engine is throttled to higher power. There is a slight decrease in the bulk discharge potential (outside the discharge cathode plume) of a few volts, which is directly connected to the decrease in the discharge voltage. Minor near-DCA plasma potential structure changes are evident for some operating conditions. Figure 15 demonstrates the two different near-DCA potential shapes for an equivalent thruster operating conditions. The plot on the left consists of a narrow plume, while the contour image on the right consists of a narrow plume with a bulge of the low-potential region near the DCA. These different structures may play an important role in the erosion of the DCA as will be discussed. It is not clear why these structures differ given thruster operation at equivalent conditions. 

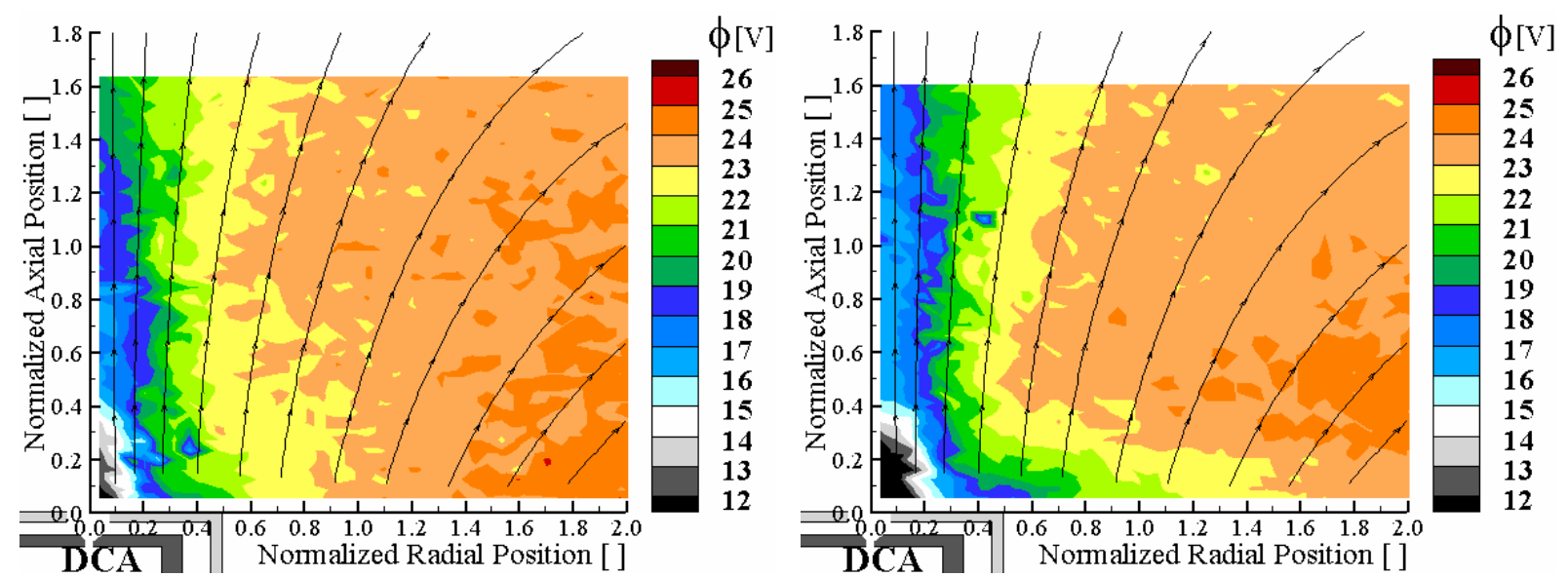

Figure 15. Neat-DCA LM4 floating emissive probe potentials for FEP TOC $0 a-V_{s}=275 \mathrm{~V}, \mathrm{~J}_{\mathrm{b}}=1.00 \mathrm{~A}$ (left) and FEP TOC $0 \mathrm{~b}-\mathrm{V}_{\mathrm{s}}=275 \mathrm{~V}, \mathrm{~J}_{\mathrm{b}}=1.00 \mathrm{~A}$ (right).

There are very little variations in the near-DCA potentials as the engine is throttled to higher power. The potential field is dictated by the confinement of electrons by the axial magnetic field near the DCA. A slight decrease in potential outside the cathode plume is observed for the higher power settings corresponding to a decrease in the discharge voltage for these conditions. The near-DCA potential is lowest along centerline at the DCA exit plane with a minimum of approximately 12 volts. The potential rises dramatically in the radial direction off-axis almost to the discharge voltage over a distance corresponding to the keeper radius.
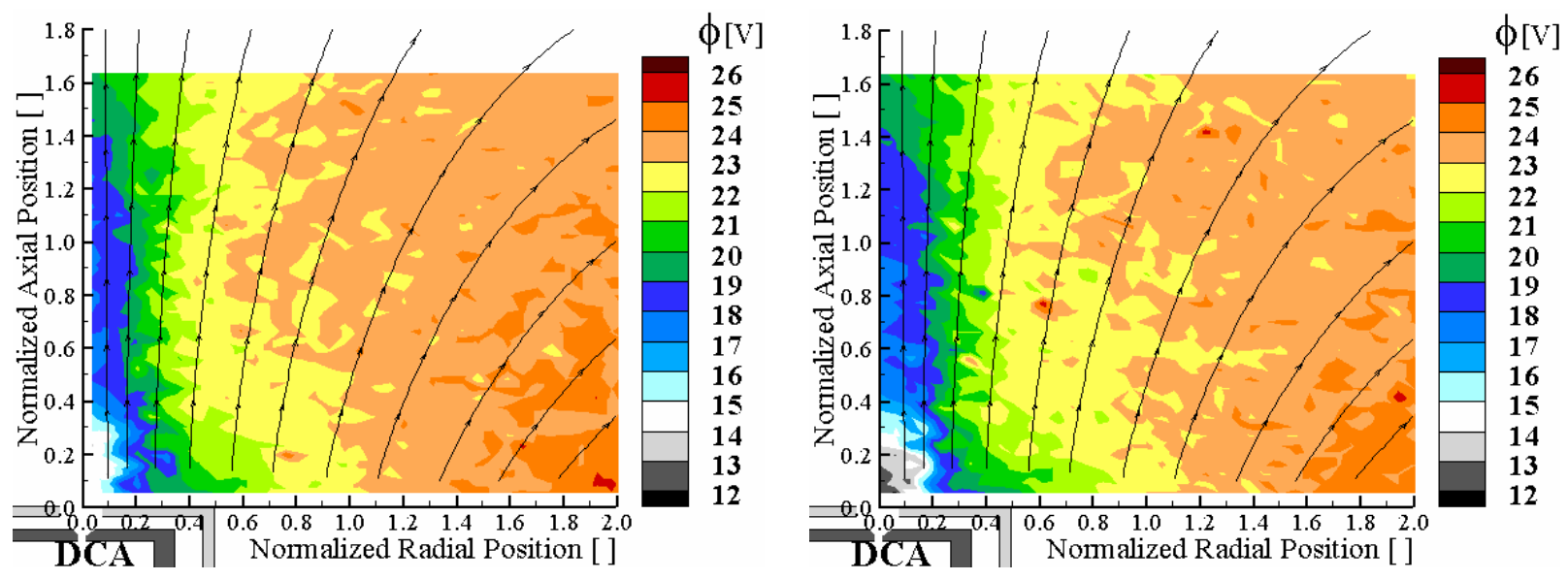

Figure 16. Near-DCA LM4 floating emissive probe potentials for FEP TOC 3a $-V_{s}=650 \mathrm{~V}, J_{b}=1.20 A$ (left) and FEP TOC 8a $-V_{s}=1179 \mathrm{~V}, J_{b}=1.20 \mathrm{~A}$ (right). 

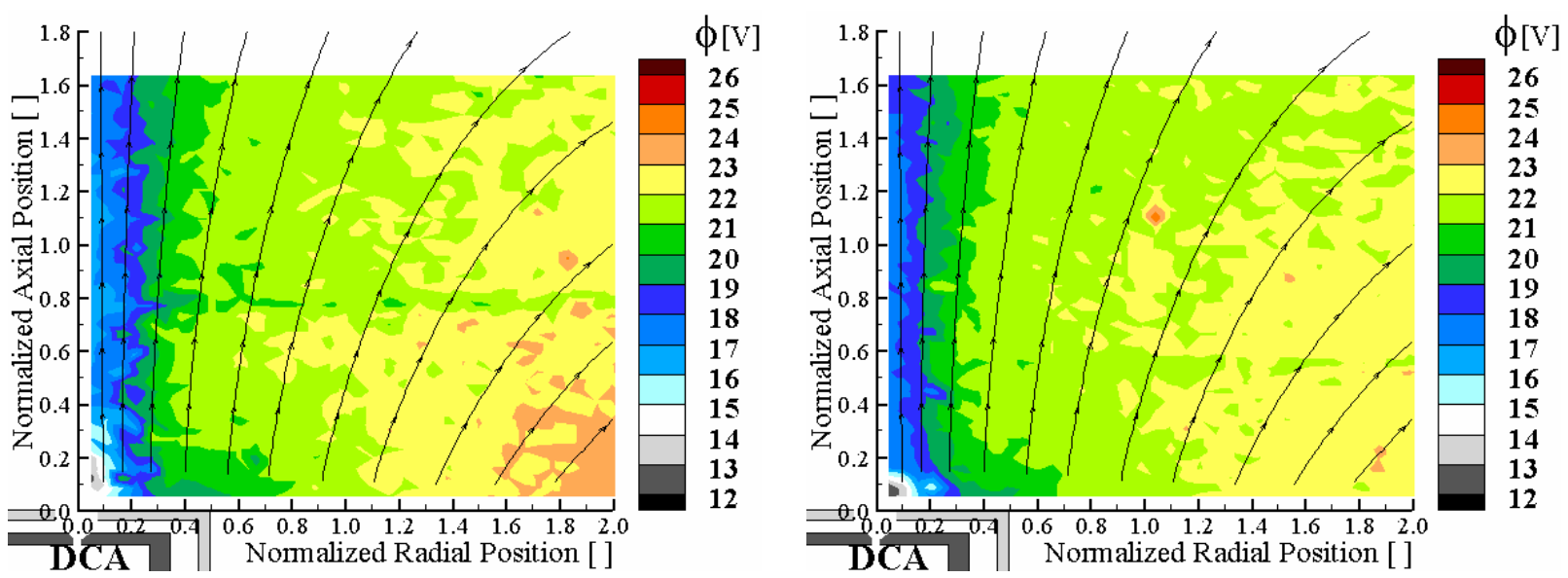

Figure 17. Near-DCA LM4 floating emissive probe potentials for FEP TOC $18-V_{s}=1179 \mathrm{~V}, J_{b}=2.00 A$ (left) and FEP TOC 32a $-V_{s}=1180 \mathrm{~V}, J_{b}=3.11 \mathrm{~A}$ (right) shifted up by 3 volts.
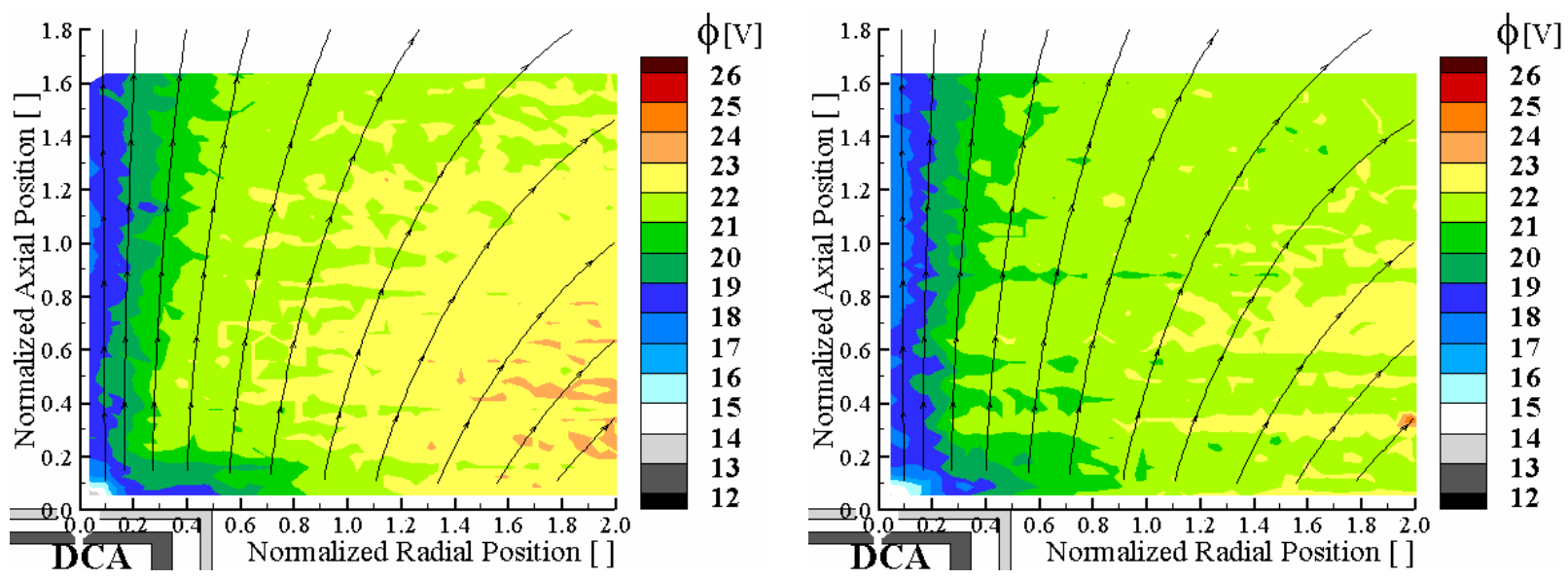

Figure 18. Near-DCA LM4 floating emissive probe potentials for FEP TOC 20b' $-V_{s}=1466 \mathrm{~V}, \mathrm{~J}_{\mathrm{b}}=\mathbf{2 . 0 0 \mathrm { A }}$ (left) shifted up by 4 volts and FEP TOC 34a' $-V_{s}=1501 \mathrm{~V}, J_{b}=3.10$ A (right) shifted up by 4.

\section{Discussion}

The plasma potential mappings closely follow the magnetic field streamlines as the higher potential regions exist in regions between magnetic cusps near the anode, where electrons have a difficult time reaching. The axial magnetic field near the DCA confines electrons to a narrow plume significantly reducing radial electron diffusion. Conversely, axial electron conductivity is enhanced. The enhanced axial electron conductivity tends to smooth out axial structures eliminating the potential-hill theory. The restricted radial movement of electrons drives the sharp potential transition between the two plasmas. There is a distinct discharge cathode plume rising from $\sim 12$ volts to the within a few volts of the discharge voltage within a keeper radius in the radial direction. A more gradual increase is observed in the axial direction. The confinement of electrons establishes a free-standing potential gradient in the radial direction that is commonly termed a double layer. The double layer acts to increase the radial diffusion of electrons from the discharge cathode plume towards the bulk discharge plasma. The double layer conversely accelerates ions from the bulk discharge plasma towards the discharge cathode plume. This acceleration contributes to the erosion of the discharge cathode.

It is evident that the magnetic field is responsible for the formation of the double layer and the resulting double layer is aligned with the axial magnetic field. The voltage gradients are highest at the cathode where the axial magnetic field is strongest giving rise to a radially directed erosion component. The plasma potential mappings follow the same general structure with moderate differences very close to the DCA for some cases. 


\section{A. Sputtering Data and Erosion Calculation}

The application of the measured parameters to calculate DCA erosion rates is difficult due to the lack of an accurate low-energy, heavy-ion sputter yield description. The sputtering yield, $Y$, is a statistical variable defined as the mean number of atoms removed from a solid target per incident particle. For application to DCA erosion, the sputtering yield will indicate the mean number of molybdenum atoms removed from the keeper face per incident xenon ion:

$$
Y \equiv \frac{\text { atoms removed }}{\text { incident particle }} .
$$

The semi-empirical sputtering yield formulae, commonly used for sputtering yield calculation, rely on a sputtering threshold energy, defined as the minimum kinetic energy of the bombarding particle for sputtering to occur, as a fit parameter. The range of values for the sputtering threshold for the $\mathrm{Xe}^{+}$-Mo system found in literature is $15-62 \mathrm{eV}$. This broad range of values illustrates the ill-defined nature of the sputtering threshold energy which prevents calculation of low-energy sputtering yields with any degree of confidence. As a result, semi-empirical formulae are not used.

Doerner, et al., recently measured molybdenum sputtering yields during xenon ion bombardment in the energy range of 10 and $200 \mathrm{eV}$ utilizing the standard weight loss technique and spectroscopically in the plasma. ${ }^{43}$ Doerner's results indicate threshold energy on the order of $15 \mathrm{eV}$ for xenon sputtering of molybdenum. ${ }^{44}$ The spectroscopic sputter yields and standard weight loss yields calculated by Doerner compare nicely to each other and to existing low-energy $\mathrm{Xe}^{+}$-Mo data taken by other researchers validating the results. ${ }^{44}$ As a result, Doerner's data will serve as the best indication of low-energy normal-incidence sputtering yield for the $\mathrm{Xe}^{+}$-Mo system. The Doerner sputter yield versus energy data are log-log plotted and a sixth order polynomial fit to the resulting graph. From this fit, a completely experimental determination of the normal incident sputtering yield of the low-energy $\mathrm{Xe}^{+}$-Mo system can be determined as a function of energy:

$$
\begin{aligned}
Y_{\text {Doerner }}(E) & =\exp \left\{-0.372304[\ln (E)]^{6}+9.48041[\ln (E)]^{5}-100.046[\ln (E)]^{4}\right. \\
+ & \left.560.276[\ln (E)]^{3}-1758.24[\ln (E)]^{2}+2940.48[\ln (E)]-2064.3\right\} .
\end{aligned}
$$

Numerous sputtering investigations demonstrated that sputtering yield has a definite angular dependence. ${ }^{45-50}$ An empirical formula for the angular dependence of the sputtering is given by Yamamura, et al., as: ${ }^{48,51}$

$$
\left(\frac{Y(\theta)}{Y(0)}\right)=\cos ^{-19.96} \theta \cdot \exp \left[-13.55\left(\cos ^{-1} \theta-1\right)\right]
$$

In Eq. 7, the numeric factors are energy-dependent fit parameters determined from $100-\mathrm{eV}$ xenon ions impacting a molybdenum target and $\mathrm{Y}(0)$ is the sputtering yield at normal incidence. ${ }^{51}$ The exponent fit parameter, 19.96, carries the threshold effect and is a function of the ratio $\mathrm{E} / \mathrm{E}_{\mathrm{th}}$. Figure 19 illustrated the angular dependence of the sputtering yield calculated for xenon ions on a molybdenum target calculated from Eq. 7. The maximum angular correction factor is approximately 3.7 corresponding to an angle of 48 degrees. 


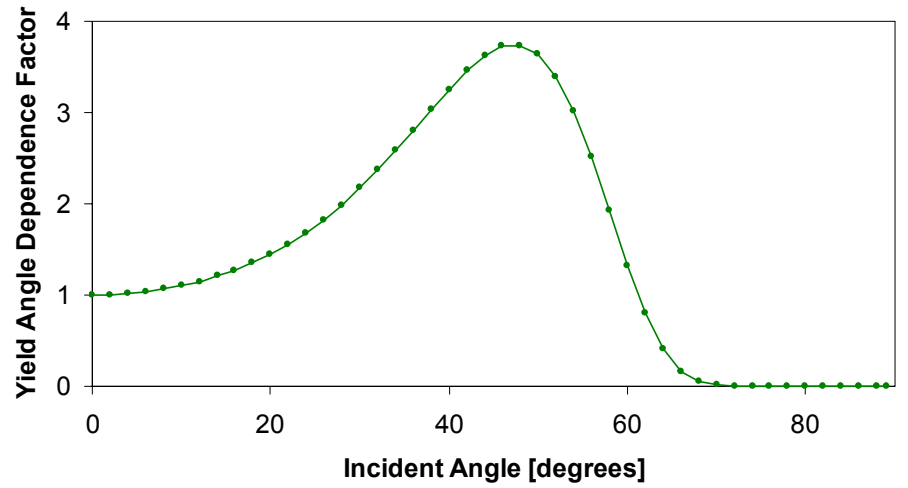

Figure 19: Angular dependence factor for the sputtering yield utilizing experimental data at $100 \mathrm{eV}$ for the fitting coefficients.

The erosion rate for the NEXT thruster during the 2000-hr wear test can been estimated based upon the expected plasma parameters at the wear test operating condition. Because the LM4 engine is restricted to the low-to-mid power throttling, number densities and plasma potentials are estimated for the wear test conditions. The plasma potentials for the both $30-\mathrm{cm}$ NSTAR and $40-\mathrm{cm}$ NEXT engines demonstrate very little variation in the near-DCA structure. ${ }^{23,28}$ The plasma potentials found outside the double layer are approximately two volts above the discharge voltage. To simulate the operating condition of the NEXT wear test, operated at a discharge voltage of 23.5 volts, a plasma potential outside the double layer of 25.5 volts is used. ${ }^{52}$

As observed, the near-DCA potentials exhibited curved profiles in some cases that would tend to focus ions on the keeper face. The bulging of the higher potential regions near the DCA effectively increases the flux of directed ions striking the DCA. This results because the double layer edge is bowed into a higher density region. It is not evident why certain operating conditions exhibit a more bowed versus collimated potential field near the DCA.

Given an ion starting potential in the bulk discharge located just outside the double layer, 25.5 volts (determined from plasma potential mappings), and the presheath potential of the discharge cathode keeper at mid-radius of approximately 19 volts (also determined from plasma potential mappings) a presheath ion energy is determined. A range of incident ion angles are used to illustrate the angular dependence in calculated erosion rates. Based upon the potential mappings and LIF measured velocimetry on a $30-\mathrm{cm}$ NSTAR thruster operated in the keepered configuration, and confirmed by the curvature of the near-DCA potential mappings of the $30-\mathrm{cm}$ and $40-\mathrm{cm}$ ion thrusters; an incident presheath angle of approximately 60 degrees (with respect to the keeper normal) is expected. $^{13,53}$

The ion is assumed accelerated through the sheath normal to the surface by the potential between the presheath potential of 19 volts and the discharge keeper floating potential of 4.5 volts, determined from the LM4 plasma potential contours and thruster telemetry. A through-sheath energy and angle is calculated giving the incident ion energy with angular dependence. The flux of the ions towards the keeper is determined based upon the directed flux from the higher potential region by directed acceleration towards the keeper. The location just outside the double layer, for the highest LM4 power condition investigated, corresponds to a number density from Langmuir probe data on the LM4 thruster of roughly $5 \times 10^{11} \mathrm{~cm}^{-3} .{ }^{40}$ To accurately predict the erosion rate, the double-to-single current ratio is also needed. Doubly-charged ions will impact the keeper with twice the energy of a singly-charged ion. Williams measured the double-to-single current ratio for both $30-\mathrm{cm}$ and $40-\mathrm{cm}$ engines finding that the ratio increased with discharge voltage for constant discharge current and with discharge current for constant discharge voltage. ${ }^{34}$ For a beam current of $3.52 \mathrm{~A}$, and discharge voltage of 24 volts, Williams measured a double-to-single current ratio of $0.18 .^{34}$

An assumed erosion geometry, based upon the NSTAR keeper erosion observed in wear testing, is used to convert the volumetric erosion rate to an eroded depth of the keeper per time (which is typically reported). The calculation of the erosion rate expected in the NEXT wear test is illustrated in Table 2. The expected erosion rate for the wear test condition, based on Doerner's curve-fit adjusted for angular dependence, is $49 \mu \mathrm{m} / \mathrm{khr}$. 
Table 2: NEXT calculated wear rate for the wear test condition and assuming a double-to-single ratio of 0.18 .

\begin{tabular}{|c|c|c|c|c|c|c|c|c|c|c|}
\hline \multirow[b]{2}{*}{$\begin{array}{l}\text { Number } \\
\text { density }\end{array}$} & \multirow[b]{2}{*}{$\begin{array}{c}\text { Plasma } \\
\text { potential }\end{array}$} & \multirow[b]{2}{*}{$\begin{array}{l}\text { Potential } \\
\text { at sheath }\end{array}$} & \multirow[b]{2}{*}{ Vck-cc } & \multicolumn{3}{|c|}{ Pre-sheath } & \multicolumn{3}{|c|}{ Through-sheath } & \multirow{2}{*}{$\begin{array}{c}\text { Doerner } \\
\text { Erosion } \\
\text { Rate } \\
\end{array}$} \\
\hline & & & & Energy & Velocity & Angle & Energy & Velocity & Angle & \\
\hline$\left[\mathrm{cm}^{\wedge}-3\right]$ & [V] & [V] & [V] & {$[\mathrm{eV}]$} & {$[\mathrm{m} / \mathrm{s}]$} & [degrees] & {$[\mathrm{eV}]$} & {$[\mathrm{m} / \mathrm{s}]$} & [degrees] & $\begin{array}{c}\text { [micron I } \\
\text { khr] }\end{array}$ \\
\hline $5 . E+11$ & 25.5 & 19 & 4.5 & 7 & 3090 & 0 & 21 & 5553 & 0 & 24 \\
\hline $5 . E+11$ & 25.5 & 19 & 4.5 & 7 & 3090 & 30 & 21 & 5553 & 16 & 30 \\
\hline 5.E+11 & 25.5 & 19 & 4.5 & 7 & 3090 & 60 & 21 & 5553 & 29 & 49 \\
\hline $5 . E+11$ & 25.5 & 19 & 4.5 & 7 & 3090 & 75 & 21 & 5553 & 33 & 58 \\
\hline
\end{tabular}

With a detailed picture of the discharge plasma structure, it appears as though the DCA erosion can be explained as a result of ions (doubles and singles) accelerated across the double layer imparting energies on the order of the drop across the double layer itself plus the fall voltage through the keeper sheath. There are several ways to reduce the DCA erosion:

- Decreasing the relative potential drop between the bulk discharge ( discharge voltage) plasma and the keeper potential via reduction in discharge voltage or biasing of the keeper electrode.

- Alteration of the discharge keeper to a more sputter resistant material (i.e., titanium or carbon).

- Modification of the double layer structure via the magnetic field design.

- Reduction of the doubly-charged ion production by reducing the discharge voltage and/or discharge oscillations.

Before application of these suggestions, care must be taken to ensure their feasibility and that they do not introduce additional factors to the DCA erosion or thruster operation. The biasing of the discharge keeper will involve a separate power supply complicating the electronics, adding weight, and serving as a loss to the thruster performance. The discharge voltage may not be decreased indefinitely as the voltage must be high enough to efficiently ionize the xenon propellant. The first ionization potential of xenon is $12.13 \mathrm{eV}$ and the second ionization potential is $33.3 \mathrm{eV}$ for reference. ${ }^{44}$ It seems unreasonable to reduce the discharge voltage below the 23.5 volts of the NEXT wear test.

Some potential substitute keeper materials include carbon, beryllium, and titanium. Doerner, et al. investigated erosion of molybdenum, titanium, carbon, and beryllium for near threshold energies. Their results indicate that carbon is measured to erode at a rate of 20 times slower than molybdenum at $50 \mathrm{eV}$ incident ion energy. ${ }^{44}$ Carbon materials, however, introduce another erosion mechanism besides sputter erosion. Chemical erosion yield of carbon due to the formation of volatile $\mathrm{CO}$ molecules is approximately 0.4 for the temperature regime in ion thrusters. ${ }^{44}$ The volatile behavior of carbon, when exposed to small amounts of oxygen will require substantial testing before it can be used with confidence, given the impurities of the xenon propellant and oxides present in the cathode insert itself.

The sputter yields of titanium and beryllium indicate that the larger mass difference for these two materials compared to molybdenum reduces the yields accordingly. For $50 \mathrm{eV}$ ions, titanium sputters about 1.5 times slower than molybdenum, and beryllium sputters about 4.3 times slower. ${ }^{44}$ The selection of titanium or beryllium as the keeper material would decrease the NEXT erosion rate from roughly $49 \mu \mathrm{m} / \mathrm{khr}$ to $32 \mu \mathrm{m} / \mathrm{khr}$ (titanium) and 11.4 $\mu \mathrm{m} / \mathrm{khr}$ (beryllium) according to the erosion calculation in this investigation.

The best immediate way to reduce DCA erosion is to select a keeper material whose sputtering threshold energy is large, but whose chemical yield is small. Titanium and beryllium are two such materials, though carbon (once tested) may be ideal. Maintaining a moderate discharge voltage (as low as possible without sacrificing performance) and reducing discharge voltage oscillations have a double effect of decreasing the potential fields responsible for ion acceleration and reducing the number of doubly-charged xenon molecules. Extreme care should therefore be taken to minimize the discharge voltage and discharge voltage oscillations while maintaining adequate performance. Some adjustment to the magnetic field topography of the ion engine will shape the double layer and can reduce the flux of ions to the keeper face. 


\section{Conclusions}

A method of mapping the discharge plasma potentials inside a $40-\mathrm{cm}$ NEXT engine is demonstrated. Plasma potential mappings confirm the existence of a double layer potential structure between the discharge cathode plume and the bulk discharge plasma consistent with similar testing in the 30-cm NSTAR thruster. The LM4 double layer structure is closely aligned with the axial magnetic field near the DCA resulting in a narrow discharge cathode plume.

The measured plasma potentials for the LM4 thruster, over the permissible operating conditions, indicate very little change in the overall structure with increasing thruster power. A bulk discharge plasma potential of a few volts above the discharge voltage is observed at a distance on the order of the discharge keeper radius away from DCA centerline in the radial direction. Two different near-DCA potential structures are observed. A narrow cathode plume of low plasma potential is observed in all operating conditions, but a bulge near the DCA forms for certain thruster operating conditions. It is not understood why the near-DCA bulge forms.

A sputtering yield, and erosion rate, is calculated for the 2000-hr NEXT wear test based upon the measured plasma potentials and the discharge voltage of the wear test, measured Langmuir probe parameters in the LM4, LIF ion velocimetry, and the NEXT double-to-single current ratio measured downstream of the ion optics for the NEXT engine at full power. The calculated keeper face erosion rate is calculated to be $49 \mu \mathrm{m} / \mathrm{khr}$, slightly less than the measured 2000-hr and 8200-hr NSTAR wear test erosion rates.

\section{Acknowledgments}

We would like to thank Mr. Michael Patterson of the NASA Glenn Research Center (GRC) for the financial support of this research through research grant NAG3-2216 and for use of government equipment. We would like to acknowledge Dr. John Foster (grant monitor) and Dr. George Williams who have been principal contacts at NASA GRC. We would also like to thank the technicians at NASA GRC, Terry Larrow at the University of Michigan, and Bob Roman who assisted in building the LM4 thruster.

\section{References}

${ }^{1}$ Choueiri, E. Y., "A Critical History of Electric Propulsion: The First 50 Years (1906 - 1956)," Journal of Propulsion and Power, Vol. 20, No. 2, pp. 193-203, March-April 2004.

${ }^{2}$ Polk, J. E., Kakuda, R. Y., Anderson, J. R., Brophy, J. R., Rawlin, V. K., Patterson, M. J., Sovey, J. S. and Hamley, J., "Performance of the NSTAR Ion Propulsion System on the Deep Space One Mission," AIAA-2001-0965, 39th AIAA Aerospace Sciences Meeting and Exhibit Joint Propulsion Conference, Reno, NV, January 8-11, 2001.

${ }^{3}$ Sengupta, A., Brophy, J. R. and Goodfellow, K. D., "Status of the Extended Life Test of the Deep Space 1 Flight Spare Ion Engine after 30,352 Hours of Operation," AIAA-2003-4558, 39th AIAA / ASME / SAE / ASEE Joint Propulsion Conference, Huntsville, AL, July 20-23, 2003.

${ }^{4}$ Patterson, M. J., Rawlin, V. K., Sovey, J. S., Kussmaul, M. and Parkes, J., "2.3 kW Ion Thruster Wear Test," AIAA-19952516, 31st AIAA / ASME / SAE / ASEE Joint Propulsion Conference, San Diego, CA, July 10-12.

${ }^{5}$ Polk, J. E., Patterson, M. J., Brophy, J. R., Rawlin, V. K., Sovey, J. S., Myers, R. M., Blandino, J. J., Goodfellow, K. D. and Garner, C. E., "A 1000 Hour Wear Test of the NASA NSTAR Ion Thruster," AIAA-1996-2784, 32nd AIAA / ASME / SAE / ASEE Joint Propulsion Conference, Lake Buena Vista, FL, July 1-3.

${ }^{6}$ Polk, J. E., Anderson, J. R., Brophy, J. R., Rawlin, V. K., Patterson, M. J., Sovey, J. S. and Hamley, J., "An overview of the results from an 8200 hour wear test of the NSTAR ion thruster," AIAA-1999-2446, 35th AIAA / ASME / SAE / ASEE Joint Propulsion Conference, Los Angeles, California, June 20-24, 1999.

${ }^{7}$ Polk, J. E., Anderson, J. R., Brophy, J. R., Rawlin, V. K., Patterson, M. J. and Sovey, J. S., "The Effect of Engine Wear on Performance in the NSTAR 8000 Hour Ion Engine Endurance Test," AIAA-1997-0869, 33rd AIAA / ASME / SAE / ASEE Joint Propulsion Conference, Seattle, WA, July 6-9.

${ }^{8}$ Oleson, S.Katz, I., "Electric Propulsion for Project Prometheus," AIAA-2003-5279, 39th AIAA / ASME / SAE / ASEE Joint Propulsion Conference, Huntsville, AL, July 20-23, 2003.

${ }^{9}$ Oleson, S. R., "Electric Propulsion Technology Development for the Jupiter Icy Moons Orbiter Project," AIAA-2004-3449, 40th AIAA / ASME / SAE / ASEE Joint Propulsion Conference, Fort Lauderdale, Florida, July 11-14, 2004.

${ }^{10}$ Cupples, M., Coverstone, V. and Woo, B., "Application of Solar Electric Propulsion to a Comet Surface Sample Return Mission," AIAA-2004-3804, 40th AIAA / ASME / SAE / ASEE Joint Propulsion Conference, Fort Lauderdale, FL, July 11-14.

${ }^{11}$ Oh, D., Benson, S., Witzberger, K. and Cupples, M., "Deep Space Mission Applications for NEXT: NASA's Evolutionary Xenon Thruster," AIAA-2004-3806, 40th AIAA / ASME / SAE / ASEE Joint Propulsion Conference, Fort Lauderdale, FL, July $11-14$.

${ }^{12}$ Benson, S.Patterson, M. J., "Development status of NEXT: NASA's evolutionary xenon thruster," IEPC-03-0288, 28th International Electric Propulsion Conference, Toulouse, France, March 17-21, 2003. 
${ }^{13}$ Williams, G. J., Smith, T. B. and Gallimore, A. D., "30 cm Ion Thruster Discharge Cathode Erosion," IEPC-01-306, 27th International Electric Propulsion Conference, Pasadena, CA, October 15-19, 2001.

${ }^{14}$ Williams, G. J., Smith, T. B., Patrick, T. A. and Gallimore, A. D., "Characterization of the FMT-2 discharge cathode plume," IEPC-99-104, 26th International Electric Propulsion Conference, Kitakyushu, Japan, October 1999.

${ }^{15}$ Farnell, C. C., Williams, J. D. and Wilbur, P. J., "Characteristics of energetic ions emitted from hollow cathodes," IEPC-03072, 28th International Electric Propulsion Conference, Toulouse, France, March 17-21, 2003.

${ }^{16}$ Foster, J. E.Patterson, M. J., "Plasma emission characteristics from a high current hollow cathode in an ion thruster discharge chamber," AIAA-2002-4102, 38th AIAA / ASME / SAE / ASEE Joint Propulsion Conference, Indianapolis, IN, July 7$10,2002$.

${ }^{17}$ Foster, J. E.Patterson, M. J., "Characterization of Downstream Ion Energy Distributions from a High Current Hollow Cathode in a Ring Cusp Discharge Chamber," AIAA-2003-4865, 39th AIAA / ASME / SAE / ASEE Joint Propulsion Conference, Huntsville, AL, July 20-23, 2003.

${ }^{18}$ Foster, J. E., Soulas, G. C. and Patterson, M. J., "Plume and Discharge Plasma Measurements of an NSTAR-type Ion thruster," AIAA-2000-3812, 36th AIAA / ASME / SAE / ASEE Joint Propulsion Conference, Huntsville, AL., July 16-19, 2000.

${ }^{19}$ Sengupta, A., Goebel, D. M., Fitzgerald, D., Owens, A., Tynan, G. and Doerner, R., "Experimentally Determined Neutral Density and Plasma Parameters in a $30 \mathrm{~cm}$ Ion Engine," AIAA-2004-3613, 40th AIAA / ASME / SAE / ASEE Joint Propulsion Conference, Fort Lauderdale, FL, July 11-14, 2004.

${ }^{20}$ Goebel, D. M., Jameson, K. K., Watkins, R. M. and Katz, I., "Hollow Cathode and Keeper-Region Plasma Measurements using Ultra-Fast Miniature Scanning Probes," AIAA-2004-3430, 40th AIAA / ASME / SAE / ASEE Joint Propulsion Conference, Fort Lauderdale, FL, July 11-14, 2004.

${ }^{21}$ Herman, D. A.Gallimore, A. D., "A high-speed axial reciprocating probe positioning system for interrogating the discharge plasma of a $30 \mathrm{~cm}$ ion thruster," AIAA-2002-4256, 38th AIAA / ASME / SAE / ASEE Joint Propulsion Conference, Indianapolis, IN, July 7-10, 2002.

${ }^{22}$ Herman, D. A.Gallimore, A. D., "Comparison of Discharge Plasma Parameters in a 30-cm NSTAR Type Ion Engine with and without Beam Extraction," AIAA-2003-5162, 39th AIAA / ASME / SAE / ASEE Joint Propulsion Conference, Huntsville, Alabama, July 20-23, 2003.

${ }^{23}$ Herman, D. A.Gallimore, A. D., "Near Discharge Cathode Assembly Plasma Potential Measurements in a $30 \mathrm{~cm}$ NSTARtype Ion Engine amidst Beam Extraction," AIAA-2004-3958, 40th AIAA / ASME / SAE / ASEE Joint Propulsion Conference, Fort Lauderdale, FL, July 11-14.

${ }^{24}$ Herman, D. A., McFarlane, D. S. and Gallimore, A. D., "Discharge plasma parameters of a $30 \mathrm{~cm}$ ion thruster measured without beam extraction using a high-speed axial reciprocating probe positioning system," IEPC-03-0069, 28th International Electric Propulsion Conference, Toulouse, France, March 17-21, 2003.

${ }^{25}$ Soulas, G. C., Domonkos, M. T. and Patterson, M. J., "Performance Evaluation of the NEXT Ion Engine," AIAA-20035278, 39th AIAA / ASME / SAE / ASEE Joint Propulsion Conference, Huntsville, AL, July 20-23, 2003.

${ }^{26}$ Soulas, G. C., Kamhawi, H., Patterson, M. J., Britton, M. A. and Frandina, M. M., "NEXT Ion Engine 2000 Hour Wear Test Results," AIAA-2004-3791, 40th AIAA / ASME / SAE / ASEE Joint Propulsion Conference, Fort Lauderdale, FL, July 1114.

${ }^{27}$ Hoskins, W. A., Wilson, F. C., Polaha, J., Talerico, L., Patterson, M. J., Soulas, G. C. and Sovey, J. S., "Development of a Prototype Model Ion Thruster for the NEXT System," AIAA-2004-4111, 40th AIAA / ASME / SAE / ASEE Joint Propulsion Conference, Fort Lauderdale, FL, July 11-14.

${ }^{28}$ Herman, D. A., "The Use of Electrostatic Probes to Characterize the Discharge Plasma Structure and Identify Discharge Cathode Erosion Mechanisms in Ring-Cusp Ion Thrusters," Thesis, Dept. of Aerospace Engineering, University of Michigan, Ann Arbor, MI, 2005.

${ }^{29}$ Haas, J. M., "Low-Perturbation Interrogation of the Internal and Near-field Plasma Structure of a Hall thruster using a High-Speed Probe Positioning System," Ph. D. Thesis, Dept. of Aerospace Engineering, University of Michigan, Ann Arbor, MI, 2001.

${ }^{30}$ Haas, J. M., Gallimore, A. D., McFall, K. and Spanjers, G. G., "Development of a high-speed, reciprocating electrostatic probe system for Hall thruster interrogation," Review of Scientific Instruments, Vol. 71, No. 11, pp. 4131, November 2000.

${ }^{31}$ Haas, J. M.Gallimore, A. D., "Characterization of the internal plasma structure of a 5kw hall thruster," IEPC-99-078, 26th International Electric Propulsion Conference, Kitakyushu, Japan, October 1999.

${ }^{32}$ Hofer, R. R.Gallimore, A. D., "Recent Results from Internal and Very-Near-Field Plasma Diagnostics of a High Specific Impulse Hall thruster," IEPC-03-037, 28th International Electric Propulsion Conference, Toulouse, France, March 17-21, 2003.

${ }^{33}$ Williams, G. J., Smith, T. B., Gulczinski, F. S., Beal, B. E., Gallimore, A. D. and Drake, R. P., "Laser Induced Fluorescence Measurement of Ion Velocities in the Plume of a Hall Effect Thruster," AIAA-1999-2424, 35th AIAA / ASME / SAE / ASEE Joint Propulsion Conference, Los Angeles, CA, June 20-23, 1999.

${ }^{34}$ Williams, G. J., Domonkos, M. T. and Chavez, J. M., "Measurement of doubly charged ions in ion thruster plumes," IEPC01-310, 27th International Electric Propulsion Conference, Pasadena, CA, October 15-19, 2001.

${ }^{35}$ Hershkowitz, N.Cho, M. H., "Measurement of Plasma Potential using Collecting and Emitting Probes," Journal of Vacuum Science and Technology A, Vol. 6, No. 3, pp. 2054-2059, May/June 1988.

${ }^{36}$ Hershkowitz, N., "Chapter 3: How Langmuir Probes Work," Plasma Diagnostics, O. Auciello and D. L. Flamm, eds., Academic Press, Inc., Orlando, pp. 113-184,1989. 
${ }^{37}$ Hershkowitz, N., Nelson, B., Pew, J. and Gates, D., "Self-emissive Probes," Review of Scientific Instruments, Vol. 54, No. 1, pp. 29-34, January 1983.

${ }^{38}$ Demidov, V. I., Ratynskaia, S. V. and Rypdal, K., "Electric Probes for Plasmas: The Link Between Theory and Instrument," Review of Scientific Instruments, Vol. 73, No. 10, pp. 3409-3439, October 2002.

${ }^{39}$ Mott-Smith, H. M.Langmuir, I., "Langmuir Probe Theory," Physical Review, Vol. 28, pp. 727, 1926.

${ }^{40}$ Herman, D. A.Gallimore, A. D., "Discharge Chamber Plasma Structure of a 40-cm NEXT-type Ion Engine," AIAA-20054250, 41st AIAA / ASME / SAE / ASEE Joint Propulsion Conference, Tucson, AZ, July 10-13, 2005.

${ }^{41}$ Ye, M. Y.Takamura, S., "Effect of space-charge limited emission on measurements of plasma potential using emissive probes," Physics of Plasmas, Vol. 7, No. 8, pp. 3457-3463, August, 2000.

${ }^{42}$ Schott, L., "Chapter 11: Electrical Probes," Plasma Diagnostics, W. Lochte-Holtgreven, ed., North-Holland Publishing Company, Amsterdam, pp. 668-731,1968.

${ }^{43}$ Doerner, R. P.Goebel, D. M., "Sputtering Yields of Ion Thruster Grid and Cathode Materials during Very Low Xenon Plasma Bombardment," AIAA-2003-4561, 39th JPC, Huntsville, AL, July 20-23.

${ }^{44}$ Doerner, R. P., Whyte, D. G. and Goebel, D. M., "Sputtering Yield Measurements during Low Energy Xenon Plasma Bombardment," Journal of Applied Physics, Vol. 93, No. 9, pp. 5816-5823, May 1.

${ }^{45}$ Wehner, G., "Influence of the Angle of Incidence on Sputtering Yields," Journal of Applied Physics, Vol. 30, No. 11, pp. 1762-1765, November 1959.

${ }^{46}$ Cheney, K. B.Pitkin, E. T., "Sputtering at Acute Incidence," Journal of Applied Physics, Vol. 36, No. 11, pp. 3542-3544, November 1965.

${ }^{47}$ Tartz, M., Neumann, H., Fritsche, B., Leiter, H. J. and Esch, J., "Investigation of Sputter Behavior of Ion Thruster Grid Materials," AIAA-2004-4114, 40th JPC, Fort Lauderdale, FL, July 11-14.

${ }^{48}$ Yamamura, Y., "An Empirical Formula for Angular Depedence of Sputtering Yields," Radiation Effects, Vol. 80, pp. 5772, 1984.

${ }^{49}$ Yamamura, Y., "Threshold Energies of Light-Ion Sputtering and Heavy-Ion Sputtering as a Function of Angle of Incidence," Nuclear Instruments and Methods in Physics Research B2, pp. 627-630, 1984.

${ }^{50}$ Kolasinski, R. D., "Sputtering Yields of Ion Thruster Materials at Oblique Incidence," AIAA-2004-4110, 40th JPC, Fort Lauderdale, FL, July 11-14.

${ }^{51}$ Duchemin, O. B., "A Review of Low Energy Sputtering Theory and Experiments," IEPC-1997-068, 25th IEPC, Cleveland, Oh, Aug. 24-28.

${ }^{52}$ Soulas, G. C., Domonkos, M. T., Kamhawi, H. and Gardner, M. M., "Status of the NEXT ion engine wear test," Huntsville, AL, Jul 20-23, 2003.

${ }^{53}$ Williams, G. J., "The Use of Laser-Induced Fluorescence to Characterize Discharge Cathode Erosion in a $30 \mathrm{~cm}$ Ring-Cusp Ion thruster," Ph. D. Thesis, Dept. of Aerospace Engineering, University of Michigan, Ann Arbor, MI., 2000. 